\title{
The Effects of Word Frequency for Japanese Kana and Kanji Words in Naming and Lexical Decision: Can the Dual-Route Model Save the Lexical-Selection Account?
}

\author{
Yasushi Hino \\ Chukyo University
}

\author{
Stephen J. Lupker \\ University of Western Ontario
}

\begin{abstract}
The effects of word frequency were examined for Japanese Kanji and Katakana words in 6 experiments. The sizes of frequency effects were comparable for Kanji and Katakana words in the standard lexical decision task. In the standard naming task, the frequency effect for Katakana words was significantly smaller than that for Kanji words. These results were consistent with the lexical-selection account of frequency effects offered by dual-route models. Contrary to this account, however, frequency effects were smaller for Katakana words than for Kanji words in go/no-go naming tasks, in which participants were asked to name a stimulus aloud only if it was a word. This Frequency $\times$ Script Type interaction was not the result of using a go/no-go task because the interaction disappeared in the go/no-go lexical decision task. These results pose a strong challenge for the lexical-selection account of frequency effects offered by dual-route models.
\end{abstract}

The word frequency effect, that is, the finding that high-frequency words are responded to faster than lowfrequency words, is one of the most robust and well-known effects in word recognition research (e.g., Balota \& Chumbley, 1984, 1985; Forster \& Chambers, 1973; Monsell, Doyle, \& Haggard, 1989; Paap, McDonald, Schvaneveldt, \& Noel, 1987; Rubenstein, Garfield, \& Millikan, 1970; Seidenberg, Waters, Barnes, \& Tanenhaus, 1984; Waters \& Seidenberg, 1985). As such, all models of word recognition have included a mechanism to account for this effect, and, in fact, the evaluations of these models have often centered on an examination of these particular mechanisms.

In classical word recognition models, word frequency effects have been explained by assuming either frequencysensitive lexical representations or a frequency-ordered serial search. For example, Morton's (1969) logogen model and McClelland and Rumelhart's (1981; Rumelhart \& McClelland, 1982) interactive-activation model explain frequency effects by assuming frequency-sensitive lexical units. According to these models, lexical units are assumed to be evidence-collecting devices with adjustable thresholds. Upon presentation of a visual input, activation levels in lexical units increase at rates proportionate to the visual similarity between the input and the spelling of the word represented by the lexical unit. This process continues until one of these units is activated over threshold. The amount of activation required to reach the threshold is an inverse

Yasushi Hino, Department of Psychology, Chukyo University, Nagoya, Aichi, Japan; Stephen J. Lupker, Department of Psychology, University of Western Ontario, London, Ontario, Canada.

We thank Derek Besner, Karalyn Patterson, and especially Ken Forster for their comments on earlier versions of the article.

Correspondence concerning this article should be addressed to Yasushi Hino, Department of Psychology, Chukyo University, 101-2 Yagotohonmachi Syowaku, Nagoya, Aichi 466, Japan. Electronic mail may be sent to hino@sccs.chukyo-u.ac.jp. function of word frequency. Thus, frequency effects in these models are due to the fact that lexical units for higher frequency words require less activation to reach threshold.

Becker's (1980) verification model (see also Paap, McDonald, et al., 1987; Paap, Newsome, McDonald, \& Schvaneveldt, 1982) and Forster's (1976) lexical search model assume that a frequency-ordered sequential matching process is involved in selecting the appropriate lexical representation. According to the verification model, for example, lexical units are activated when they are orthographically similar to a visual input. The activated lexical units are next serially compared with the visual information stored in a visual buffer in descending order of word frequency. Thus, in these models, frequency effects result because higher frequency words are checked earlier in the sequential matching process.

Although these two types of models assume quite different underlying mechanisms for explaining word frequency effects, both types of models are based on the idea that the process of selecting the lexical unit appropriate to the presented word is a central process in word recognition. They also share the assumption that frequency effects occur during this selection process. In the literature, this process has typically been referred to as lexical access. At the same time, however, this particular use of the term lexical access has not been universal. Thus, to avoid confusion, we avoid using the term here. Rather, we refer to this selection process as lexical selection. What we would like the reader to note is that, within the framework of these models, this process of lexical selection only refers to the process of selecting the appropriate lexical unit. It does not refer to any of the processes involved in retrieving phonological, syntactic, or semantic information. This distinction is an important when evaluating these models because, according to the models, although frequency effects are assumed to arise during the 
process of selecting a lexical unit, no such assumptions are made about any of the subsequent, code-retrieval processes.

Because these models all share the assumption that frequency effects occur only during the lexical-selection process, Balota and Chumbley (1984) noted that the models all predict that the sizes of frequency effects should be identical across word recognition tasks if these tasks all involve this common process. To evaluate this prediction, Balota and Chumbley (1984) examined the effects of word frequency in lexical decision, naming, and categoryverification tasks with identical word stimuli. Contrary to the models' predictions, however, frequency effects were significantly larger in the lexical decision task than in the naming task and were absent in category-verification tasks. Thus, Balota and Chumbley (1984) argued that although the lexical-selection process might be frequency sensitive, it is decision-making processes that are mainly responsible for frequency effects in lexical decision tasks and pronunciationrelated processes that are mainly responsible for frequency effects in naming tasks (see also Balota \& Chumbley, 1985).

Balota and Chumbley (1984) characterized the decisionmaking operations in a lexical decision task by suggesting that they are based on familiarity-meaningfulness (FM) values calculated for both words and nonwords. Because the FM values are highly correlated with word frequency, FM values for higher frequency words would be relatively greater. Thus, higher frequency words would be easily discriminable from nonwords on the basis of the FM values. For lower frequency words, however, FM values are relatively lower, so that their FM values overlap with those of nonwords. Because the FM values do not provide enough of a clue to discriminate low-frequency words from nonwords, Balota and Chumbley (1984) assumed that more analytic processing would be required for making decisions. Thus, the decision-making process would be slower for lower frequency words.

Balota and Chumbley's (1984) decision-making account has, however, been challenged recently by a number of researchers working within the dual-route tradition. The fundamental assumption of dual-route models (e.g., Coltheart, 1978; Coltheart, Curtis, Atkins, \& Haller, 1993; Monsell, 1990, 1991; Monsell et al., 1989; Paap, McDonald, et al., 1987; Paap \& Noel, 1991; Patterson \& Coltheart, 1987 ) is that there are two independent parallel processes for retrieving phonology. One process, referred to as the lexical route, is based on the idea that after readers select the appropriate lexical unit (determined by an analysis of the word's orthographic representation), a phonological code becomes available in an essentially holistic and relatively automatic fashion. That is, phonological coding is assumed to occur only after selecting a lexical representation. The other process, the assembly route, is based on the idea that phonological codes can be generated from subword-level orthographic codes by applying spelling-to-sound correspondence rules. That is, phonological coding is accomplished based on sublexical, graphemic representations (or larger orthographic units) by calculating the corresponding phonemes and then assembling them to produce a phonological representation.
According to dual-route models, the sublexical coding process is assumed to be frequency insensitive. That is, although this process might be sensitive to subword-level variables such as bigram frequencies, it would not be sensitive to word frequency because it does not refer to lexical knowledge in converting graphemes to their corresponding phonemes. The lexical route, however, is frequency sensitive, and thus this model also has, as one of its central assumptions, the classic assumption made by word recognition models that frequency effects are due to the lexical-selection process.

As researchers working within the dual-route framework have argued, this framework provides a straightforward alternative account of Balota and Chumbley's (1984) differential word frequency effects in lexical decision and naming tasks (Monsell, 1990, 1991; Monsell et al., 1989; Paap, McDonald, et al., 1987; Paap \& Noel, 1991). The argument is that one is unlikely to observe full-blown frequency effects in naming because the frequency-insensitive sublexical coding process could be effectively used for at least some of the words in a naming task. However, because the lexical decision task requires a word-nonword discrimination, the task typically requires that participants determine that the letter string has a lexical representation (e.g., Coltheart, 1978; Coltheart et al., 1993). As a consequence, word frequency effects should be more evident in a lexical decision task.

More specifically, Monsell and colleagues (Monsell, 1990, 1991; Monsell et al., 1989) have argued that because the lexical route is frequency sensitive and, hence, fast for higher frequency words, the information necessary to produce a vocal response would be available much sooner from this route than from the relatively slower assembly route. For lower frequency words, however, because the lexical route is somewhat slower, the assembly route may produce an output slightly before, or at approximately the same time as, the lexical route. When these outputs are consistent (e.g., for words that obey the spelling-to-sound correspondence rules of the speaker's language), a vocal response may be initiated faster than when the phonological code could come only from the lexical route. As such, word frequency effects would be expected to shrink.

One implication of this dual-route explanation is that if phonological codes are retrieved only from the lexical route in a naming task, the size of the word frequency effect should be identical to that in a lexical decision task because both tasks would fully involve the frequency-sensitive lexical-selection process. Paap, McDonald, et al. (1987) used an affixed-naming task to examine this possibility. In this task, words (e.g., life) were presented with either a prefix (e.g., nevlife) or a suffix (e.g., lifeger). The readers' task was to find a word in the letter string and to read aloud just the word as quickly as possible. Paap, McDonald, et al. (1987) argued that because lexical decision operations are implicitly required prior to phonological coding in this task, the phonological codes used should always be those made available from the lexical route. Thus, Paap, McDonald, et al. (1987) predicted that the frequency effect in the affixednaming task should be virtually identical to that in a lexical 
decision task using these same words. The results were consistent with this prediction. Although the word frequency effect was smaller in a standard naming task (31-ms effect) than in the lexical decision task (99-ms effect), the effects were almost identical in the lexical decision task and the affixed-naming task (107-ms effect).

Monsell et al. (1989), however, pointed out that Paap, McDonald, et al.'s (1987) results could also be explained by Balota and Chumbley's (1984) decision-making account. Because the affixed-naming task is assumed to require lexical decision operations prior to phonological coding, the task should involve not only a lexical-selection component but also a decision-making component. If so, frequency effects would be identical for the affixed-naming and lexical decision tasks even if the effects were mostly due to the decision-making process.

Monsell et al. (1989) instead attempted to examine this issue by contrasting words that can be named accurately by the sublexical coding process (i.e., the assembly route) with words that cannot. Some words (e.g., regular words like save-gave, five-dive) can be pronounced correctly by sublexical coding because their spelling-to-sound relations follow the correspondence rules of the language. Other words (e.g., exception words like have, give) cannot because their spelling-to-sound relations violate those rules. Thus, as will be described below, Monsell et al. were able to vary the degree to which sublexical coding was presumably involved in the naming process by using both regular and exception words.

According to Monsell et al. (1989), the ability of the sublexical coding process to produce the correct phonological code should be an important variable in determining the size of frequency effects in naming tasks. Following a review of previous literature, Monsell et al. documented a tendency for word frequency effects in naming tasks to be greater for words that cannot be pronounced accurately using spelling-to-sound correspondence rules (i.e., the exception words). Thus, Monsell (1991) suggested that "the more that naming depends on transcoding at a lexical level, and the less on sublexical transcoding, between spelling and sound, the larger the frequency effect" (p. 177). In the extreme, if sublexical coding simply could not be accomplished successfully for a certain type of word, phonological coding must be done at the lexical level for those words (i.e., via the lexical route). If so, and if the lexical-selection process is the only process that is frequency sensitive, there should be equal size frequency effects in the naming and lexical decision tasks for that type of word.

To test this idea, Monsell et al. (1989) used disyllabic words in lexical decision and naming experiments. They noted that a majority of disyllabic words are pronounced with initial stress in English. Thus, stress-initial disyllabic words (e.g., forest) are regular, but stress-final words (e.g., forget) are exceptional in terms of stress assignment in English. Therefore, sublexical coding would not lead to the correct naming response for stress-final disyllabic words. The result, according to the dual-route account, is that phonological coding for stress-final words would tend to be done at the lexical level. As such, word frequency effects should be larger for stress-final words than for stress-initial words in a naming task. In contrast, in the lexical decision task, frequency effects should be identical for stress-initial and stress-final words because lexical selection would be required for both types of words. Finally, because the lexical-selection process tends to be required for stress-final words in a naming task as well as in a lexical decision task, the frequency effects for stress-final words should be essentially equivalent in the two tasks.

Although, contrary to expectations, word frequency effects were somewhat larger for stress-initial words (104-ms effect) than for stress-final words (75-ms effect) in the lexical decision task, the remainder of Monsell et al.'s (1989) results were consistent with expectations. In particular, word frequency effects were numerically larger for stress-final words (74-ms effect) than for stress-initial words (59-ms effect) in the naming task, and the frequency effects for stress-final words were identical in the naming and the lexical decision tasks. Although Monsell et al. acknowledged the existence of a decision-making process in lexical decision tasks, on the basis of these results, their conclusion was that either the decision-making process runs in parallel with the lexical-selection process or, if not, that the decisionmaking process is not frequency sensitive. Thus, their conclusion was that, as classical models have suggested, word frequency effects are essentially due to the lexicalselection process. ${ }^{1}$

Although Monsell et al.'s (1989) results do provide support for their dual-route account of frequency effects in naming and lexical decision tasks, their results are less compelling than one might hope (see also Balota \& Chumbley, 1990). For example, as noted above, there was a clear difference in the size of the frequency effects for the two word types in lexical decision even though the stress-initial and stress-final words had been equated on word frequency. As a second example, as Balota and Chumbley also noted, the Stress $\times$ Frequency interaction in the naming task was not significant. (Using these same words, Brown, Lupker, \& Colombo, 1994, obtained almost identical results: a 59-ms frequency effect for the stress-initial words and a $72-\mathrm{ms}$ frequency effect for the stress-final words. Here also the interaction was not significant, despite there being three times as many participants.) If one assumes that the stressfinal words were virtually always named by means of the lexical route and that the decision-making process plays essentially no role in producing frequency effects in lexical

\footnotetext{
${ }^{1}$ Part of Balota and Chumbley's (1984) argument against the lexical-selection account was based on the fact that they and others (e.g., Anderson \& Reder, 1974; Millward, Rice, \& Corbett, 1975) did not observe frequency effects in category-verification tasks, tasks that clearly should have required lexical selection. Monsell et al. (1989), however, did report a frequency effect in their categorization task as have others (e.g., Forster \& Shen, 1996). Although it clearly is important to determine what factors are responsible for these conflicting results, the questions of (a) whether there are frequency effects in semantic tasks and (b), if so, whether those effects require a lexical-selection explanation or can be accounted for in terms of decision-making processes are not ones that we were rying to deal with here.
} 
decision (assumptions that seem warranted based on the virtually identical frequency effects for the stress-final words in the two tasks), this lack of an interaction implies that the stress-initial words were also named quite often by means of the lexical route. If so, Monsell et al.'s account would predict that the sizes of the frequency effects for stress-initial words in the naming and lexical decision tasks should have been fairly similar, a result that did not occur.

One possible reason for both of these problems may have been that the two word types were not equated on familiarity. In fact, three of the low-frequency stress-final words proved to be so unfamiliar that they had to be removed from the analysis. The effect of this removal may have been that the low-frequency stress-final words remaining were actually more familiar than the low-frequency stress-initial words. Assuming that the two sets of high-frequency words were fairly equal in familiarity, one would expect that the effect of frequency on lexical selection would be smaller for the stress-final words in both tasks. If so, both the lack of an interaction in the naming task and the smaller frequency effect for stress-final words in the lexical decision task could be accounted for.

Unfortunately, there is another possible explanation of the lack of a Stress $\times$ Frequency interaction in the naming task. That is, Monsell et al.'s (1989) analysis of the effects of stress pattern may be incorrect and there really is very little difference in the relative contributions of the two routes for the two word types. One could argue, for example, that because the words used in these experiments were generally regular in terms of spelling-to-sound correspondence rules, the basic phonology for both word types came from the assembly route. One could further argue that readers do not assign a stress-initial stress pattern by default but rather by analyzing the phonological code made available by the lexical route. If this analysis is correct and the relative contributions of the two routes were similar for the two word types, the implication would be that Monsell et al.'s stress manipulation did not actually provide a viable means for testing their theoretical claims.

Another point that should be made is that the cross-task comparisons that did work out exactly as predicted are complicated by the fact that the interpretation of frequency effects in lexical decision tasks is less than straightforward. The reason is that lexical decision latencies and effect sizes (e.g., frequency effects) can be noticeably affected by the nature of the nonwords (e.g., James, 1975; Shulman \& Davison, 1977; Shulman, Hornak, \& Sanders, 1978; Stone \& Van Orden, 1993). In particular, when the nonwords are not very wordlike (i.e., unpronounceable nonwords), effect sizes decrease, whereas the use of pseudohomophones (nonwords that are pronounced like words and hence are more difficult to classify as nonwords) causes effects to increase.

The problem this causes is not a problem for Monsell et al.'s (1989) dual-route account, per se. In fact, the account itself actually has no great difficulty explaining these types of effects. The argument would be that with nonwords that are not very wordlike, it is not necessary to isolate a unique lexical unit on at least some subset of the word trials, because lexical decisions can sometimes be made on the basis of other information (e.g., overall initial lexical activity), information that is not frequency sensitive. The result is a reduction in the frequency effect. However, with pseudohomophones, because they sound like words, an extra, spell-checking process is invoked, a process that could be frequency sensitive, which thus increases the size of the frequency effect.

Rather, the problem is that because the size of the frequency effect in a lexical decision task is affected by the nature of the nonwords, the validity of comparing effect sizes across tasks becomes an issue. For cross-task comparisions to be valid, the selected nonwords in the lexical decision task need to be wordlike enough to prevent decisions from being made without lexical selection being completed for each word; but they must not be so wordlike that they, themselves, allow a lexical unit to be selected and thus necessitate a spell check. Although Monsell et al. (1989) undoubtedly selected their nonwords with these types of considerations in mind, there is no way to know exactly how successful they were. Thus, even if their theoretical position is correct, one must regard the observed frequency effects in their lexical decision task (and, in fact, in most lexical decision tasks) as a less-than-perfect estimate of the effects of frequency on lexical selection. As a result, one must regard the success of the cross-task comparisons with at least a bit of skepticism.

Finally, one additional logical point needs to be made. Although models like that of Monsell et al. (1989) do predict equivalent frequency effects in different tasks, models that account for frequency effects in terms of processes other than lexical selection do not necessarily predict different size effects in different tasks. There is no reason, for example, that the effect of frequency on the decision-making process in Balota and Chumbley's (1984) lexical decision account must be different in size from the effect of frequency on whatever pronunciation-related processes are involved in naming (i.e., phonological coding process, output production process). Similarly, models that postulate no lexicon or lexical-selection process at all (e.g., Plaut \& McClelland, 1993; Plaut, McClelland, Seidenberg, \& Patterson, 1996; Seidenberg \& McClelland, 1989) may also have no serious trouble accounting for cross-task similarities in frequency effects, assuming, of course, that they can account for naming and lexical decision performance in the first place (see Besner, Twilley, McCann, \& Seergobin, 1990; Fera \& Besner, 1992, for criticisms of the ability of these models to account for lexical decision performance). Because Monsell et al.'s account does specifically predict equivalent frequency effects in different tasks, however, consistent replication of this pattern across stimulus sets, laboratories, and languages would suggest that it should be regarded as more than a coincidence. Further, on the basis of parsimony, unless there are other data discrediting Monsell et al.'s account, theirs should really be considered the superior account.

The primary purpose of the present research was to provide another evaluation of the viability of Monsell et al.'s (1989) proposal. In the first two experiments, we simply 
attempted to test again Monsell et al.'s explanation for the difference in the sizes of frequency effects in naming and lexical decision tasks. One important change was that we obtained familiarity values for all stimuli in order to equate word types on familiarity as well as frequency. In subsequent experiments we attempted to provide a more complete evaluation of this account by changing the nature of the tasks. The most important difference between these experiments and those of Monsell et al., however, was that we used Japanese words, which were written in either Kanji or Katakana script. As noted earlier, it is unclear that the relative contributions of the two routes are much different for stress-initial and stress-final disyllabic English words. As we describe in the following section, the script-type manipulation in Japanese is much less susceptible to this criticism.

\section{Japanese Scripts}

There are two types of scripts in the Japanese language: syllabic Kana (either Katakana or Hiragana) and logographic Kanji. One important difference is the extent to which the orthography encodes phonological information. Because each Kana character corresponds to a single pronunciation, Kana is considered a shallow orthography that has virtually no spelling-to-sound irregularities. Kanji characters, however, generally correspond to at least two pronunciations, which are the so-called kun-reading and on-reading pronunciations. The kun-readings are of Japanese origin and have been assigned to each Kanji character on the basis of its meaning. The on-readings are of Chinese origin. When Kanji characters were imported from China, their pronunciations were imported with them. Because most Kanji characters do not correspond to a single pronunciation, Kanji is considered a deep orthography in which spelling-to-sound correspondences are, in essence, arbitrary.

Although some Japanese words consist of a single character, most words (in all scripts) consist of multiple characters. For words that are usually written in Katakana script, the majority are three or four characters in length (i.e., $55.35 \%$ of the Katakana words in word frequency norms for Japanese are three or four characters in length; National Language Research Institute, 1970). Most words that are usually written in Kanji script, however, are two characters in length (i.e., $79.86 \%$ of Kanji words contained in those same frequency norms are two characters in length).

Given these quite different types of scripts, Morton and Sasanuma (1984) have argued that there are processing differences in reading Kana and Kanji words. They argued that "kana is read phonetically and kanji is read visually" ( $p$. 40). That is, because phonological codes can be derived from sublexical character units for Kana-written words and then assembled into a complete phonological code, lexical selection (and subsequent retrieval of semantic information) would always be mediated by prelexical phonology for those words. For Kanji-written words, however, lexical selection would always be accomplished directly based on the orthographic information. Therefore, in terms of phonological coding, their arguments imply that sublexical coding is always used for Kana-written words but that phonological coding for Kanji-written words is always accomplished at the lexical level.

Assuming that this difference in phonological coding between Kana- and Kanji-written words is real, there should be no effect of word frequency or familiarity in naming Kana-written words because Kana-written words are assumed to be pronounced only through the frequencyinsensitive sublexical coding process. As Besner and Hildebrandt (1987) have demonstrated, however, Morton and Sasanuma's (1984) analysis is not entirely correct. Besner and Hildebrandt examined the effects of word frequency by using Katakana-written words that were either orthographically familiar or completely unfamiliar. In particular, orthographic familiarity was manipulated by using either Katakana words or Katakana transcriptions of Kanji words. Katakana words are words that are usually printed in Katakana (e.g., foreign loan words). Thus, the orthography of these words is familiar to the readers, which could, in theory, allow naming to be driven by the lexical route. In contrast, Kanji words are usually written in Kanji and are only rarely written in Katakana. Thus, when Kanji words are transcribed into Katakana, the orthographic familiarity for their Katakana transcriptions should be quite low. Naming responses should therefore be driven only by the assembly route.

Naming latencies for these two types of words written in Katakana were compared to examine whether there are orthographic familiarity effects in a naming task. Besner and Hildebrandt's (1987) results showed that naming latencies were faster for Katakana words than for Katakana transcriptions of Kanji words. This orthographic familiarity effect suggested that there is at least some lexical influence in the process of naming Katakana words. Thus, Besner and Hildebrandt concluded that both lexical and sublexical coding are used in producing phonological codes for words written in Katakana (see also Besner \& Smith, 1992; Buchanan \& Besner, 1993, concerning evidence for lexical involvement in the naming of Kana-written words).

For words written in Kanji, however, more recent evidence has supported Morton and Sasanuma's (1984) claim that coding is done only at the lexical level. In particular, Wydell, Butterworth, and Patterson (1995) demonstrated that there is no effect of print-to-sound consistency in naming Kanji words. That is, naming latencies were compared for Kanji words that consisted of Kanji characters with only a single pronunciation (the consistent condition) and Kanji words that consisted of Kanji characters with multiple pronunciations (the inconsistent condition). If the sublexical coding process were active for these stimuli, one would expect there to be competition for words in the inconsistent condition and, hence, longer naming latencies. Wydell et al., however, could not observe any sign of consistency effects through their six experiments, thus supporting the claim that phonological coding for Kanji words is only accomplished at the lexical level.

According to Besner and Hildebrandt's (1987) and Wydell et al.'s (1995) arguments, therefore, Katakana and Kanji words provide a reasonable parallel to regular and exception words in English and, more important, they provide a very 
good means for testing Monsell et al.'s (1989) account. That is, phonological codes for Japanese Katakana words can be generated by either lexical or sublexical coding processes. The correct pronunciations for Kanji words, however, appear to be generated only through the lexical coding process. Thus, following Monsell and colleagues' (Monsell, 1990, 1991; Monsell et al,, 1989) arguments, word frequency effects for Kanji words should be larger than those for Katakana words in a naming task but of equivalent size in a lexical decision task. Further, word frequency effects for Kanji words should be similar in naming and lexical decision tasks. To examine these predictions, we conducted a lexical decision task (Experiment 1) and a naming task (Experiment 2) with both Kanji and Katakana words. ${ }^{2}$

\section{Experiment 1}

\section{Method}

Participants. Twenty-six undergraduate students from Chukyo University participated in this experiment for course credit. All were native Japanese speakers and had normal or corrected-tonormal vision.

Stimuli. Fifty-eight Kanji words and fifty-eight Katakana words were collected on the basis of word frequency norms for Japanese (National Language Research Institute, 1970). The Kanji words were all two characters long, and the Katakana words were three or four characters long. Half of the Kanji and Katakana words were high-frequency words. Frequency counts for the high-frequency words were greater than 50 per 3 million, whereas frequency counts for the low-frequency words were all 5 per 3 million.

After collecting 116 words, we asked 28 people to rate the experiential familiarity for these words. These individuals were all selected from the same participant pool as the experimental participants. None of them, however, participated in any of the experiments reported in this article. The 116 words were randomly ordered and listed in a questionnaire. Each word was accompanied by a 7-point scale ranging from 1 (very unfamiliar) to 7 (very familiar). We asked these individuals to rate their experiential familiarity with each word by circling the appropriate number on the scale.

On the basis of the familiarity ratings for these 116 words, 64 words were finally selected to create four word groups. The word stimuli consisted of 16 high-frequency Kanji words, 16 lowfrequency Kanji words, 16 high-frequency Katakana words, and 16 low-frequency Katakana words. That is, four word groups were created by crossing two factors, script type (Kanji or Katakana) and frequency (high or low). The experiential familiarity rating values as well as word frequency counts were quite comparable between Kanji and Katakana word groups. The number of syllables (moras) were closely matched across the four word groups. In addition, for the Kanji word groups, summed character frequencies (National Language Research Institute, 1963) were matched between highand low-frequency words. ${ }^{3}$

To assure that the four word groups had been selected properly, we conducted analyses of variance (ANOVAs) on all the relevant measures: word frequency, word length, syllabic length, and experiential familiarity ratings. For word frequency, the main effect of frequency was significant, $F(1,60)=146.41, M S E=985.65$, $p<.001$, but neither the main effect of script type, $F(1,60)=0.05$, $M S E=985.65$, nor the interaction between frequency and script type, $F(1,60)=0.05, M S E=985.65$, was significant. The same results were obtained for the experiential farniliarity ratings: frequency, $F(1,60)=134.34, M S E=0.357, p<.001$; script type, $F(1,60)=0.07, M S E=0.357$; interaction, $F(1,60)=0.13$, $M S E=0.357$. No significant effects were detected in the analysis of syllabic length: frequency, $F(1,60)=0.00, M S E=0.229 ; \mathrm{script}$ type, $F(1,60)=0.00, M S E=0.229$; interaction, $F(1,60)=0.00$, $M S E=0.229$. In the analysis of word length, however, the main effect of script type was significant, $F(1,60)=397.64, M S E=$ $0.115 ; p<.001$, because the Kanji words were all two characters long, whereas the Katakana words were three or four characters long. Finally, a $t$ test conducted to compare the summed character frequencies for high- and low-frequency Kanji words indicated that the summed character frequencies were quite comparable, $t(30)=.02$.

The experimental word stimuli are shown in the Appendix. The statistical characteristics of these words are presented in Table 1.

In addition to the experimental word stimuli, 8 filler-word stimuli (half Kanji and half Katakana words) and 72 nonword stimuli were added. Thus, the entire stimulus set consisted of 144 stimuli. To prevent participants from being able to discriminate words from nonwords without requiring the isolation of a unique lexical unit, we designed the nonwords to resemble the words as closely as possible; however, none of the nonwords was a pseudohomophone. Haif of the nonwords were Kanji nonwords. They were created by randomly pairing two Kanji characters. Thus, they were all two characters in length. The rest of the nonwords were Katakana nonwords, which were created by replacing one character from actual Katakana words. The mean length of the Katakana nonwords was 3.67 (range $=3-4$ ). Thus, string length was matched between word and nonword stimuli. In addition, the syllabic lengths (moras) for these nonwords were also matched with those for the word stimuli. The mean number of syllables was 3.67 for both Kanji and Katakana nonwords (range $=3-4) .^{4}$

Procedure. Participants were tested individually in a normally lit room. Participants were asked to make a word-nonword discrimination for stimuli that appeared on a video monitor (PC-TV455, NEC Corporation, Japan) by pressing either the "word" or "nonword" key on a keyboard. The two keys flanking the space key were used as the word and nonword keys, respectively (XFER and NFER keys on a NEC Japanese keyboard). Participants were also told that their responses should be made as quickly and as accurately as possible. Sixteen practice trials were given prior to the 144 experimental trials. During the practice trials,

\footnotetext{
${ }^{2}$ Paap, Chen, and Noel (1987) have reported data relevant to this final prediction. Chinese script, like the Japanese Kanji script that is derived from it, represents a very deep orthography. Thus, naming should essentially require use of a lexical route. Using Chinese characters, Paap, Chen, and Noel (1987) demonstrated equivalent frequency effects in lexical decision and naming tasks, a result quite consistent with Monsell et al.'s (1989) dual-route account.

${ }^{3}$ Because character-frequency norms were available for Kanji characters (National Language Research Institute, 1963) but not for Katakana characters, the summed character frequency counts were equated only for high- and low-frequency Kanji words. The Kanji character frequency counts were based on 280,094 Kanji samples.

${ }^{4}$ Generally, Kanji characters have more than one pronunciation. Thus, when Kanji nonwords are created by combining two Kanji characters, those Kanji nonwords can usually be pronounced several ways. In the present experiment, however, only the Kanji characters that had a single pronunciation were selected from a Kanji dictionary (Ogawa, Nishida, \& Akatsuka, 1977) and were used to create Kanji nonwords. Thus, because only a single pronunciation was possible, the number of syllables (moras) could be counted for these Kanji nonwords.
} 
participants were informed about their lexical decision latency and whether their response was correct after each trial. No feedback was given during the experimental trials. The order of stimulus presentation for the experimental trials was randomized for each participant.

Each trial was initiated with a $50-\mathrm{ms} 400-\mathrm{Hz}$ beep signal. Following the beep, a fixation point appeared at the center of the video monitor. One second after the onset of the fixation point, a stimulus was presented above the fixation point. The fixation point and the stimulus were presented in white on a black background. Participants were seated in front of the video monitor at a distance of about $50 \mathrm{~cm}$ and were asked to respond to the stimulus by pressing either the word or nonword key on the keyboard. Participants used their dominant hand to make the word response. The participant's response terminated the presentation of the stimulus and the fixation point. The lexical decision latencies from the onset of the stimulus to the participant's keypress and whether the response was correct were automatically recorded by a computer (NEC, PC-9801FA). The intertrial interval was $2 \mathrm{~s}$.

\section{Results}

Lexical decision latencies less than $250 \mathrm{~ms}$ or greater than $1,500 \mathrm{~ms}$ were classified as errors and excluded from the latency analyses. A total of 13 data points from the experimental word trials $(0.78 \%)$ were excluded in this fashion. Mean lexical decision latencies for correct responses and mean error rates (based on the experimental word trials) were calculated across individuals and across items, and these means were submitted to separate ANOVAs for subjects and for items, respectively. ${ }^{5}$ The mean lexical decision latencies and error rates from the subject analysis are presented in Table 2.

Word trials. In the analyses of lexical decision latencies, the main effect of frequency was significant both in the subject and in the item analyses: $F_{\mathrm{s}}(1,25)=115.31, M S E=$ $2,592.09, p<.001 ; \mathrm{F}_{\mathrm{i}}(1,60)=57.13, M S E=4,014.56, p<$ .001 , reflecting the fact that lexical decision latencies were faster for high-frequency words than for low-frequency words. The main effect of script type was also significant in both analyses, $F_{s}(1,25)=14.12, M S E=1,748.29, p<.01$, $F_{\mathrm{i}}(1,60)=4.56, M S E=4,014.56, p<.05$, reflecting the fact that lexical decision latencies were faster for Katakana words than for Kanji words. Most important, however, the

Table 1

Mean Word Frequency, Word Length, Syllable

Length, Summed Kanji Character Frequency (KCF), and Experiential Familiarity Rating (FAM) for the Stimuli in Each Condition in Experiments $1-6$

\begin{tabular}{lrrrrr}
\hline & \multicolumn{2}{c}{ Word } & Syllable & & \\
\cline { 2 - 5 } Condition & Frequency & Length & length & KCF $^{\mathrm{a}}$ & FAM \\
\hline Low frequency & & & & & \\
$\quad$ Katakana & 5.0 & 3.69 & 3.69 & - & 3.38 \\
$\quad \begin{array}{l}\text { Kanji } \\
\text { High frequency }\end{array}$ & 5.0 & 2.00 & 3.69 & 782.1 & 3.29 \\
$\quad$ Katakana & 98.3 & 3.69 & 3.69 & - & 5.06 \\
$\quad$ Kanji & 101.6 & 2.00 & 3.69 & 778.9 & 5.07 \\
\hline
\end{tabular}

anly for Kanji words.
Table 2

Mean Lexical Decision Latencies (in Milliseconds)

and Error Rates in the Standard Lexical Decision

Task of Experiment 1

\begin{tabular}{|c|c|c|c|c|c|}
\hline \multirow[b]{3}{*}{ Script type } & \multicolumn{4}{|c|}{ Word frequency } & \multirow[b]{3}{*}{ RT difference } \\
\hline & \multicolumn{2}{|r|}{ Low } & \multicolumn{2}{|r|}{ High } & \\
\hline & $M$ & Error (\%) & $M$ & Error (\%) & \\
\hline $\begin{array}{l}\text { Katakana } \\
\text { Kanji }\end{array}$ & $\begin{array}{l}639 \\
672\end{array}$ & $\begin{array}{l}19.23 \\
19.43\end{array}$ & $\begin{array}{l}534 \\
562\end{array}$ & $\begin{array}{l}2.64 \\
5.29\end{array}$ & $\begin{array}{l}105 \\
110\end{array}$ \\
\hline
\end{tabular}

Note. Mean lexical decision latencies and error rates for Katakana nonwords were $700 \mathrm{~ms}$ and $8.44 \%$, respectively; for Kanji nonwords, $747 \mathrm{~ms}$ and $17.52 \%$, respectively. $\mathrm{RT}=$ reaction time.

interaction between frequency and script type was not significant in either analysis: $F_{s}(1,25)=0.19, M S E=$ $1,006.21 ; F_{\mathrm{i}}(1,60)=0.15, M S E=4,014.56$.

In the analyses of error rates, the main effect of frequency was again significant in both analyses, $F_{s}(1,25)=83.87$, $M S E=73.38, p<.001, \mathrm{~F}_{1}(1,60)=18.82, M S E=201.22$, $p<.001$, reflecting the fact that responses to high-frequency words were more accurate than responses to low-frequency words. The main effect of script type, $F_{\mathrm{s}}(1,25)=1.11$, $M S E=48.62, F_{\mathrm{i}}(1,60)=0.17, M S E=201.22$, and the interaction between frequency and script type, $F_{\mathrm{s}}(1,25)=$ $0.74, M S E=50.84, F_{\mathrm{i}}(1,60)=0.12, M S E=201.22$, were nonsignificant in both analyses.

Nonword trials. Katakana nonwords were responded to significantly faster, $t_{\mathrm{s}}(25)=3.51, p<.01, t_{\mathrm{i}}(70)=3.27$, $p<.01$, and more accurately, $t_{s}(25)=4.64, p<.001$, $t_{\mathrm{i}}(70)=3.52, p<.01$, than Kanji nonwords.

\section{Discussion}

The main issue in Experiment 1 was whether there would be an interaction between word frequency and script type. Clear word frequency effects were observed in both the latency data and the error data for words in both scripts. There was, however, no tendency for these effects to vary as a function of script type.

There was, however, a main effect of script type. In particular, lexical decision latencies were faster for Katakana words than for Kanji words, and responses were faster and more accurate for Katakana nonwords than for Kanji nonwords. It is not clear what aspects of the Katakana-Kanji

\footnotetext{
5 Although Clark (1973) has argued that items as well as subjects should be considered as a random factor in these types of analyses, it is seldom the case that the selection of items is ever random in any sense of the term. That is, typically, the items used in these types of experiments have been selected because they satisfied an extensive set of criteria. Such is certainly the case here (e.g., see Table 1). As such, as Wike and Church (1976) and others (Cohen, 1976; Keppel, 1976; Smith, 1976) have argued, item analyses would clearly be inappropriate in the present situation. Nonetheless, for the interested reader, the results of item analyses are reported. Conclusions, however, are based only on the results from the subject analyses.
} 
difference were responsible for these differences because orthographic properties such as number of characters and orthographic complexity were not equated for our Kanji and Katakana stimuli. It is also unclear whether these differences could have any implications for the comparison of interest (i.e., the contrast between the sizes of the frequency effects). It is possible that the performance differences are simply due to the large differences in orthographic complexity between Kanji and Katakana (the reader who is unfamiliar with these two scripts should examine the stimuli in the Appendix) rather than any higher level processing differences. The fact that the effects arose for both the words and the nonwords seems to provide some support for this possibility. If so, the implications appear to be minor. One could argue, however, that because making the discrimination between words and nonwords was harder for Kanji stimuli, low-frequency Kanji words were particularly harmed, and thus the effect of frequency on lexical selection for Kanji words was overestimated. We consider this possibility further after evaluating the size of the frequency effect for naming Kanji words in Experiment 2.

\section{Experiment 2}

Having determined that, as predicted by Monsell et al.'s (1989) dual-route account, frequency effects in the lexical decision task are equivalent for Kanji and Katakana words equated on frequency and familiarity, we attempted in Experiment 2 to evaluate the other two predictions. In particular, because Katakana words can be named accurately on the basis of sublexical phonological codes, whereas Kanji words cannot, the expectation is that the frequency effect for Kanji words will be larger than that for Katakana words in a naming task. The further expectation is that the frequency effect for the Kanji words in the naming task should be essentially the same size as the frequency effect for those same words in the lexical decision task.

\section{Method}

Participants. Twenty-six undergraduate students from Chukyo University participated in this experiment for course credit. All were native Japanese speakers and had normal or corrected-tonormal vision. None had participated in Experiment 1.

Stimuli. The stimuli were the 72 words used in Experiment 1.

Procedure. Participants were asked to name a word aloud, as quickly and as accurately as possible, when it appeared on a video monitor. Participants' vocal responses were registered by a microphone connected to a voice key interfaced to a computer. A vocal response terminated the stimulus presentation. Naming latency was measured from the onset of the stimulus to the onset of the vocal response. During the experimental trials, an experimenter who was located in a different room checked the participants' responses through audio-video monitors and recorded errors. In all other ways, the procedure was identical to that of Experiment 1.

\section{Results}

A trial was considered a mechanical error if the participant's vocal response failed to trigger the voice key or some extraneous sound triggered the voice key. The mechanical errors were excluded from the data analyses. There were 15 $(0.80 \%)$ mechanical errors in total. In addition, naming latencies less than $250 \mathrm{~ms}$ or more than $1,000 \mathrm{~ms}$ were classified as errors and excluded from the latency analyses. Thus, 35 additional data points from the experimental word trials $(2.10 \%)$ were excluded in this fashion. Otherwise, the analyses were carried out in the same way as the analyses of the word trial data in Experiment 1. The mean naming latencies and error rates from the subject analysis are presented in Table 3.

In the analyses of naming latencies, the main effect of frequency was significant both in the subject and the item analyses, $F_{s}(1,25)=195.27, M S E=604.89, p<.001$, $F_{\mathrm{i}}(1,60)=27.81, M S E=2,461.16, p<.001$, reflecting the fact that naming latencies were faster for high-frequency words than for low-frequency words. The main effect of script type was also significant in both analyses, $F_{s}(1,25)=$ $162.74, M S E=2,169.94, p<.001, F_{\mathrm{i}}(1,60)=86.39$, $M S E=2,461.16, p<.001$, reflecting the fact that naming latencies were faster for Katakana words than for Kanji words. Most important, the interaction between frequency and script type was significant in both analyses: $F_{\mathrm{s}}(1,25)=$ $39.59, M S E=454.27, p<.001 ; F_{1}(1,60)=4.05, M S E=$ $2,461.16, p<.05$. In addition, planned comparisons showed that the frequency effects were significant both for Kanji words, $\mathrm{t}_{\mathrm{s}}(25)=12.80, p<.001, t_{\mathrm{i}}(30)=4.40, p<.001$, and for Katakana words, $t_{s}(25)=7.79, p<.001, t_{i}(30)=2.91$, $p<.01$. Thus, the significant interaction between frequency and script type indicates that word frequency effects were greater for Kanji words than for Katakana words.

In the analyses of error rates, the main effect of frequency was significant in both analyses, $F_{\mathrm{s}}(1,25)=42.82, M S E=$ $18.65, p<.001, F_{\mathrm{i}}(1,60)=8.96, M S E=52.05, p<.01$, reflecting the fact that responses to high-frequency words were more accurate than responses to low-frequency words. The main effect of script type was also significant in both analyses, $F_{\mathrm{s}}(1,25)=29.23, M S E=60.58, p<.001, F_{\mathrm{i}}(1$, $60)=21.00, M S E=52.05, p<.001$, reflecting the fact that responses to Katakana words were more accurate than responses to Kanji words. The interaction between frequency and script type was marginally significant in the subject analysis, $F_{s}(1,25)=4.19, M S E=17.82, p<.06$, although not in the item analysis, $F_{1}(1,60)=0.74, M S E=$ $52.05, p>.10$.

Table 3

Mean Naming Latencies (in Milliseconds) and Error Rates in the Standard Naming Task of Experiment 2

\begin{tabular}{lcccccc}
\hline & \multicolumn{4}{c}{ Word frequency } & \\
\cline { 2 - 3 } \cline { 5 - 6 } Script type & $M$ & Error (\%) & & $M$ & Error (\%) & RT difference \\
\cline { 2 - 3 } & \multicolumn{2}{c}{ Low } & & \multicolumn{2}{c}{ High } & \\
\hline Katakana & 528 & 4.92 & & 487 & 0.64 & 41 \\
Kanji & 671 & 14.15 & & 577 & 6.69 & 94 \\
\hline
\end{tabular}

Note. $\mathrm{RT}=$ reaction time. 


\section{Combined Analyses (With Lexical Decision Data From Experiment 1)}

To examine task differences directly, we also carried out combined analyses with the experimental word trial data from Experiment 1. Subject and item ANOVAs based on response latencies and error rates from Experiments 1 and 2 were carried out based on a 2 (frequency: high vs. low) $\times 2$ (script type: Kanji vs. Katakana) $\times 2$ (task type: lexical decision task vs. naming task) design. In the subject analyses, frequency and script type were treated as withinsubject factors, whereas task type was a between-subjects factor. In the item analyses, frequency and script type were between-items factors, whereas task type was a within-item factor.

In the analyses of latency data, the main effects of frequency, $F_{\mathrm{s}}(1,50)=247.98, M S E=1,598.49, p<.001$, $F_{\mathrm{i}}(1,60)=51.80, M S E=5,293.37, p<.001$, and script type, $F_{\mathrm{s}}(1,50)=144.09, M S E=1,959.12, p<.001, F_{\mathrm{i}}(1$, $60)=33.60, M S E=5,293.37, p<.001$, were significant in both analyses, whereas the main effect of task type was significant only in the item analysis, $F_{1}(1,60)=51.79$, $M S E=1,182.35, p<.001, F_{s}(1,50)=2.43, M S E=$ 27,937.37, $p>.10$.

The interaction between frequency and task type, $F_{s}(1$, $50)=12.89, M S E=1,589.49, p<.001, F_{1}(1,60)=19.97$, $M S E=1,182.35, p<.001$, and the interaction between script type and task type, $F_{s}(1,50)=48.77, M S E=$ $1,959.12, p<.001, F_{1}(1,60)=44.88, M S E=1,182.35, p<$ .001 , were significant in both analyses. The interaction between frequency and script type was significant only in the subject analysis: $F_{\mathrm{s}}(1,50)=14.98, M S E=730.24, p<$ $.001 ; F_{\mathrm{i}}(1,60)=1.45, M S E=5,293.37, p>.10$. Most important, the three-way interaction between frequency, script type, and task type was significant in the subject analysis, $F_{\mathrm{s}}(1,50)=9.91, M S E=730.24, p<.01$, although not in the item analysis, $F_{\mathrm{i}}(1,60)=2.42, M S E=1,182.35$, $p>.10$. The patterns in the error data mimicked those in the latency data.

Given the significant three-way interaction between frequency, script type, and task type in the subject analysis, the final questions concern the nature of the Frequency $\times$ Task Type interactions for each script type. Separate 2 (frequency) $\times 2$ (task type) ANOVAs for each script type confirmed that the interaction between frequency and task type was nonsignificant for the Kanji words, $F_{\mathrm{s}}(1,50)=$ $1.21, M S E=1,415.01$, reflecting the fact that the sizes of the frequency effects for Kanji words were similar in the lexical decision and the naming tasks; however, the interaction was clearly significant for Katakana words, $F_{s}(1,50)=28.60$, $M S E=913.72, p<.001$, reflecting the fact that the frequency effects for Katakana words were greater in the lexical decision task than in the naming task.

\section{Discussion}

As expected, a significant interaction between frequency and script type was observed for naming latencies. Word frequency effects were greater for Kanji words (94 ms) than for Katakana words $(41 \mathrm{~ms})$. In addition, the significant three-way interaction between frequency, script type, and task type in the combined analysis reflects the fact that frequency effects for Katakana words were much smaller in naming than in lexical decision ( $41 \mathrm{~ms}$ vs. $105 \mathrm{~ms}$ ), whereas frequency effects for Kanji words were comparable in these two tasks (94 ms vs. $110 \mathrm{~ms}$ ). These results are thus consistent with the predictions made by Monsell et al.'s (1989) dual-route account.

Slightly complicating these cross-task comparisons of frequency effects in the latency data is that the error rates were somewhat larger in the lexical decision task of Experiment 1 than in the naming task of Experiment 2, especially for low-frequency words. For these comparisons to be completely valid, error rates should have been the same across tasks. The fact that they were not implies that the support the latency data provide for Monsell et al.'s (1989) position is not as strong as one might hope. (As it turns out, however, the differential error rates are not problematic for our ultimate conclusions, which we present later.)

The similar frequency effects in naming and lexical decision for Kanji words also reflect on an issue raised earlier. As noted, the overall longer latencies for Kanji words and nonwords in Experiment 1 could be taken to mean that the word-nonword discrimination was more difficult for Kanji words than for Katakana words. If so, the observed frequency effect for Kanji words in the lexical decision task in Experiment 1 may have been a bit of an overestimate of the effect of frequency on lexical selection. The observation of a similar size effect in naming would seem to alleviate that concern. Because the naming of Kanji words does not require word-nonword discriminations, frequency effects for Kanji words in naming are, presumably, due solely to lexical selection. Therefore, the similar frequency effects for Kanji words in the two tasks suggests that the frequency effect for Kanji words in the lexical decision task was not an overestimate.

\section{Experiment 3}

Although the difference in the size of the frequency effects in Experiment 2 was quite large, before accepting the Frequency $\times$ Script Type interaction at face value, one additional issue must be resolved. Although the words used were equated on a number of dimensions, none of the word groups was matched on first phonemes. Thus, there is always the possibility that articulation-onset differences for highand low-frequency words may have differentially affected Kanji and Katakana words.

To examine this hypothesis, Experiment 3 was a delayednaming task in which the words from Experiments 1 and 2 were used. Because small frequency effects (attributed to the output production process) have been reported in the past in delayed-naming tasks (Balota \& Chumbley, 1985; see also Theios \& Muise, 1977), such effects may also be observed in this experiment. Nonetheless, because this production process should not be sensitive to the differences in character-tosound relationships for Kanji and Katakana words, our 
expectation was that any small frequency effects that might arise would be equivalent for the two word types.

\section{Method}

Participants. Twenty-six undergraduate students from Chukyo University participated in this experiment. They were paid a small amount of money for their participation. All were native Japanese speakers and had normal or corrected-to-normal vision. None had participated in the previous experiments.

Stimuli. The stimuli were the $\mathbf{7 2}$ words used in Experiments 1 and 2.

Procedure. Participants were told that a word would appear on the screen, and after some delay, it would be surrounded by brackets ([]). Participants were asked to name the word aloud as quickly and as accurately as possible as soon as the brackets appeared. Eight practice trials were given prior to the 72 experimental trials.

Each trial was initiated with a $50 \mathrm{~ms} 400-\mathrm{Hz}$ beep signal. Following the beep, a fixation point appeared at the center of the display. One second after the onset of the fixation point, a word was presented above the fixation point. Brackets surrounding the word were presented $1,500 \mathrm{~ms}$ later. The participant's vocal response terminated the stimulus presentation, and the naming latency from the onset of the brackets to the onset of the participant's response was recorded. In all other ways, the procedure was identical to that of Experiment 2.

\section{Results}

A trial was considered a mechanical error if the participant's vocal response failed to trigger the voice key or some extraneous sound triggered the voice key. The mechanical exrors were excluded from the data analyses. There were 16 $(0.85 \%)$ mechanical errors in total. In addition, when a delayed-naming latency was less than $50 \mathrm{~ms}$ or more than $1,000 \mathrm{~ms}$, the trial was considered an error. Thus, 6 additional data points from the experimental word trials $(0.36 \%)$ were considered as errors and removed from the analyses of naming latencies. Otherwise, the analyses were carried out in the same way as those in Experiment 2. The mean delayed-naming latencies and error rates from the subject analysis are presented in Table 4.

In the analyses of naming latencies, neither of the main effects nor the interaction approached significance in either analysis (all $F \mathrm{~s}<1.30$ ). The same was true in the analyses of error rates (all $F \mathrm{~s}<1.30$ ).

Table 4

Mean Naming Latencies (in Milliseconds) and Error Rates in the Delayed-Naming Task of Experiment 3

\begin{tabular}{lcccccc}
\hline & \multicolumn{4}{c}{ Word frequency } & \\
\cline { 2 - 3 } \cline { 5 - 6 } Script type & \multicolumn{2}{c}{ Low } & \multicolumn{2}{c}{ High } & \\
\cline { 2 - 3 } & & Error (\%) & & $M$ & Error (\%) & RT difference \\
\hline Katakana & 347 & 2.92 & & 341 & 1.92 & 6 \\
Kanji & 347 & 2.18 & & 344 & 2.42 & 3 \\
\hline
\end{tabular}

Note. $\quad \mathrm{RT}=$ reaction time.

\section{Discussion}

Because there were no significant effects in the delayednaming task of Experiment 3, it is unlikely that articulationonset differences among the four conditions were responsible for the interaction between frequency and script type in the standard naming task of Experiment 2 . Thus, the results of the first three experiments are quite consistent with the dual-route interpretation of frequency effects in naming and lexical decision tasks (e.g., Monsell et al., 1989).

As noted earlier, however, these results are also not inconsistent with Balota and Chumbley's (1984) suggestion that word frequency effects are mainly due to task-specific processes. It is possible to argue, for example, that the additive relationship between frequency and script type in Experiment 1 was due to the nature of the decision-making process, which is specific to the lexical decision task, whereas in the naming task (Experiment 2), the observed Frequency $\times$ Script Type interaction may have been due to the nature of task-specific, phonological-coding processes. We designed Experiment 4 to test between these alternative explanations.

\section{Experiment 4}

We have recently reported (Hino \& Lupker, 1996) a possible means for distinguishing the dual-route/lexicalselection account from Balota and Chumbley's (1984) task-specific account. In a set of studies paralleling the present ones, we examined the effects of word frequency as a function of polysemy (rather than script type) in lexical decision and naming tasks. In the lexical decision task, the sizes of frequency effects were identical for polysemous and nonpolysemous words (65-ms effects). In contrast, frequency interacted with polysemy in the naming task. That is, frequency effects were larger for nonpolysemous words (32-ms effect) than for polysemous words (12-ms effect). The crucial manipulation for distinguishing between competing explanations of the frequency effect, however, involved a go/no-go naming task in which participants were asked to name a stimulus aloud only if it was a word. In this task, as in the naming task, frequency interacted with polysemy. In particular, the frequency effect was larger for nonpolysemous words (105-ms effect) than for polysemous words (79-ms effect).

The analysis that we (Hino \& Lupker, 1996) provided was as follows. The go/no-go naming task essentially involves the quasi-sequential combination of lexical decision and naming tasks. That is, this task is assumed to involve first the lexical-selection process, which may then be followed by a decision-making process, which is presumably a taskspecific component in a lexical decision task. If the stimulus is a word, a phonological-coding process would be required in order to produce an overt pronunciation response. The phonological-coding process would be a task-specific component in a naming task.

If one assumes that this analysis of task components is essentially correct, then if frequency effects were due solely to the lexical-selection process, two predictions would 
follow. First, because there was no interaction between frequency and polysemy in the lexical decision task, there should be no interaction between these factors in the go/no-go naming task. Second, the size of the frequency effect in go/no-go naming should be the same as that in the lexical decision task. The reasoning is similar to that used by Paap, McDonald et al. (1987) in their affixed-naming task. That is, the lexical-selection and decision-making processes together produce an additive relationship between frequency and polysemy (as demonstrated by the results in the lexical decision task). These two processes should be affected in the same way in go/no-go naming. After a word decision has been made in go/no-go naming, however, a phonologicalcoding process is then required. As Paap, McDonald, et al. suggested, because lexical selection has already been accomplished, the phonological-coding process should either be completed or should follow immediately at the lexical level. In either case, frequency should not affect it because, according to the dual-route model, phonological coding done at the lexical level is not frequency sensitive. Thus, the frequency effects and the relationship between frequency and polysemy should be virtually the same in this task as in the lexical decision task. As noted, however, these predictions did not hold in our experiments (Hino \& Lupker, 1996). Frequency effects were larger in go/no-go naming than in lexical decision, and frequency did interact with polysemy in go/no-go naming.

An account that attributes frequency effects mainly to task-specific processes (decision making and phonological coding), however, can explain these results more easily. This type of account would attribute the Frequency $\times$ Polysemy interaction in the naming task to the phonological-coding process, and because this process is part of the go/no-go naming task, a similar interaction should show up in that task. Further, if one assumes that phonological-coding processes are frequency sensitive and begin only after lexical selection and decision making have essentially been completed, the frequency effect in the go/no-go naming task is expected to be somewhat larger than the frequency effect in the lexical decision task, as was observed.

Finally, it should be noted that an account that attributes frequency effects entirely to the task-specific processes, combined in a sequential fashion, would predict that the frequency effects in go/no-go naming would be approximately equal to the sum of the frequency effects in naming and lexical decision tasks, which is also essentially what we observed (Hino \& Lupker, 1996). That is, for nonpolysemous words, the 105-ms frequency effect in the go/no-go naming task was approximately equal to the sum of the 65-ms effect in the lexical decision task and the 32-ms effect in the naming task. For polysemous words, the 79-ms effect in the go/no-go naming task was also approximately equal to the $65-\mathrm{ms}$ effect in the lexical decision task plus the $12-\mathrm{ms}$ effect in the naming task. This prediction would be in contrast to that made by an account attributing much of the frequency effect to lexical selection. This type of account would predict that the sum of the effects in naming and lexical decision would be much larger than the effect in go/no-go naming, because the contribution of the lexical- selection process would be added twice in the former case and only once in the latter. Thus, we concluded that frequency effects are minimal during lexical selection and that frequency affects mainly the task-specific processes (see Hino \& Lupker, 1996). (A similar analysis led to the same conclusion about polysemy effects.)

This type of reasoning can be directly applied to the present situation in which script type (rather than polysemy) is the factor being manipulated in conjunction with frequency. If the additive and the interactive effects of frequency and script type were mainly due to the decisionmaking and phonological-coding processes, respectivelyprocesses that are assumed to occur in a quasi-sequential order in the go/no-go naming task - the task-component explanation makes a clear prediction. If a go/no-go naming task were used with the present stimuli, the expected result would be a Frequency $\times$ Script Type interaction, with a larger frequency effect for Kanji words than for Katakana words. A secondary expectation would be that the frequency effect would be larger in the go/no-go naming task than in the lexical decision task.

The dual-route account, however, would predict a different pattern of results in the go/no-go naming task. As discussed above, because the task is assumed to require a lexical decision operation prior to phonological coding, as in Paap, McDonald, et al.'s (1987) affixed-naming task, the naming response should be entirely controlled by the lexically based phonological coding process. That is, as in the lexical decision task, the go/no-go naming task would be assumed to fully involve the lexical-selection process as well as the decision-making process. At that point, a lexically based phonological code should be readily available, meaning that the assembly route would make no contribution to the naming process. Therefore, the dualroute account would predict that word frequency effects in the go/no-go naming task would be identical for Kanji and Katakana words. Further, the sizes of the effects should be essentially the same as those in the lexical decision task (Experiment 1).

To examine these alternatives, we designed Experiment 4 to be a go/no-go naming task in which the same Katakana and Kanji words from the previous experiments were used.

\section{Method}

Participants. Twenty-six undergraduate students from Chukyo University participated in this experiment for course credit. All were native Japanese speakers and had normal or corrected-tonormal vision. None had participated in the previous experiments.

Stimuli. The stimuli were the same as those used in Experiment 1.

Procedure. Participants were asked to name a stimulus aloud into a microphone only if the stimulus was a word. The stimuli remained on the video monitor either until the participant responded or until $2 \mathrm{~s}$ had elapsed. The response latency was measured from the onset of the stimulus to the onset of the participant's response. An experimenter who was located in a different room checked the participants' responses through audiovideo monitors and recorded errors. In all other ways, the procedure was the same as that of Experiment 1. 


\section{Results}

A trial was considered a mechanical error if the participant's vocal response failed to trigger the voice key or some extraneous sound triggered the voice key. The mechanical errors were excluded from the data analyses. There were 8 $(0.21 \%$ of all trials) mechanical errors in total. In addition, for word trials, response latencies less than $250 \mathrm{~ms}$ or greater than $1,500 \mathrm{~ms}$ were classified as errors and excluded from the latency analyses. Thus, 13 additional data points from the experimental word trials $(0.78 \%)$ were excluded in this fashion. Otherwise, the analyses were carried out in the same way as in Experiment 1, although there were, of course, no nonword latency data to analyze. The mean naming latencies and error rates from the subject analysis for the word trials are presented in Table 5.

Word trials. In the analysis of response latencies, the main effect of frequency was significant both in the subject and the item analyses, $\mathrm{F}_{8}(1,25)=361.77, M S E=1,609.90$, $p<.001, F_{\mathrm{i}}(1,60)=54.69, M S E=6,910.13, p<.001$, reflecting the fact that response latencies were faster for high-frequency words than for low-frequency words. The main effect of script type was also significant in both analyses, $F_{\mathrm{s}}(1,25)=31.83, M S E=4,345.03, p<.001$, $F_{\mathrm{i}}(1,60)=9.92, M S E=6,910.13, p<.01$, reflecting the fact that response latencies were faster for Katakana words than for Kanji words. Most important, the interaction between frequency and script type was significant in the subject analysis, $F_{s}(1,25)=13.43, M S E=1,394.56, p<$ .01 , although not in the item analysis, $F_{\mathrm{i}}(1,60)=0.74$, $M S E=6,910.13$. Planned comparisons further showed that the frequency effects were significant both for Kanji words, $t_{\mathrm{s}}(25)=14.15, p<.001, \mathrm{t}_{\mathrm{i}}(30)=5.47, p<.001$, and for Katakana words, $t_{\mathrm{s}}(25)=14.13, p<.001, \mathrm{t}_{\mathrm{i}}(30)=4.98$, $p<.001$. Thus, the significant Frequency $\times$ Script Type interaction was due to the fact that the frequency effect was greater for Kanji words than for Katakana words.

In the analyses of error rates, the only significant effect was the main effect of frequency in both analyses, $F_{\mathrm{s}}(1$, 25) $=37.46, M S E=84.87, p<.001, F_{\mathrm{i}}(1,60)=14.70$, $M S E=133.74, p<.001$, reflecting the fact that responses to high-frequency words were more accurate than responses to low-frequency words. Neither the main effect of script type, $F_{\mathrm{s}}(1,25)=2.67, M S E=37.24, p>.10, F_{\mathrm{i}}(1,60)=0.46$, $M S E=133.74, p>.10$, nor the interaction between frequency and script type, $\mathrm{F}_{\mathrm{s}}(1,25)=1.03, M S E=52.26$,

Table 5

Mean Response Latencies (in Milliseconds) and Error Rates in the Go/No-Go Naming Task of Experiment 4

\begin{tabular}{|c|c|c|c|c|c|}
\hline \multirow[b]{3}{*}{ Script type } & \multicolumn{4}{|c|}{ Word frequency } & \multirow[b]{3}{*}{ RT difference } \\
\hline & \multicolumn{2}{|r|}{ Low } & \multicolumn{2}{|r|}{ High } & \\
\hline & $M$ & Error $(\%)$ & $M$ & Enror $(\%)$ & \\
\hline Katakana & 750 & 11.06 & 627 & 1.44 & 123 \\
\hline Kanji & 850 & 14.46 & 673 & 1.96 & 177 \\
\hline
\end{tabular}

Note. Mean error rates for Katakana nonwords and Kanji nonwords were $0.97 \%$ and $1.71 \%$, respectively. RT = reaction time. $p>.10, F_{\mathrm{i}}(1,60)=0.26, M S E=133.74, p>.10$, was significant in either analysis. It should be noted that most of these errors (78\%) involved a failure to respond rather than an incorrect pronunciation.

Nonword trials. The difference in error rates between Katakana and Kanji nonwords was not significant: $t_{s}(25)=$ $1.04, p>.10 ; t_{\mathrm{i}}(70)=0.99, p>.10$.

\section{Combined Analyses (With Lexical Decision Data From Experiment 1)}

To compare the sizes of frequency effects in the present experiment with those in Experiment 1, we also carried out combined analyses with the experimental word trial data from Experiment 1. Subject and item ANOVAs based on response latencies and error rates from Experiments 1 and 4 were carried out based on a 2 (frequency: high vs. low) $\times 2$ (script type: Kanji vs. Katakana) $\times 2$ (task type: lexical decision task vs. go/no-go naming task) design. In the subject analyses, frequency and script type were treated as within-subject factors, whereas task type was a betweensubjects factor. In the item analyses, frequency and script type were between-items factors, whereas task type was a within-item factor.

In the analyses of response latencies, the following main effects were significant both in the subject and the item analyses: frequency, $F_{\mathrm{s}}(1,50)=408.32, M S E=2,101.00$, $p<.001, \mathrm{~F}_{\mathrm{i}}(1,60)=63.53, M S E=9,414.08, p<.001$; script type, $F_{s}(1,50)=45.93, M S E=3,046.66, p<.001$, $F_{\mathrm{i}}(1,60)=8.38, M S E=9,414.08, p<.01 ;$ and task type, $\mathrm{F}_{\mathrm{s}}(1,50)=18.12, M S E=43,785.52, p<.001, \mathrm{~F}_{\mathrm{i}}(1,60)=$ $289.80, M S E=1,510.61, p<.001$.

The interaction between 'frequency and task type, $F_{\mathrm{s}}(1$, $50)=11.15, M S E=2,101.00, p<.01, F_{\mathrm{i}}(1,60)=6.11$, $M S E=1,510.61, p<.025$, and the interaction between script type and task type, $F_{\mathrm{s}}(1,50)=7.57, M S E=3,046.66$, $p<.01, F_{\mathrm{i}}(1,60)=5.30, M S E=1,510.61, p<.05$, were significant in both analyses. The interaction between frequency and script type was significant in the subject analysis, $F_{s}(1,50)=9.45, M S E=1,200.39, p<.01$, although not in the item analysis, $F_{\mathrm{i}}(1,60)=0.49, M S E=$ $9,414.08, p>.10$. Most important, the three-way interaction between frequency, script type, and task type was also significant in the subject analysis, $F_{s}(1,50)=6.31, M S E=$ $1,200.39, p<.025$, although not in the item analysis, $F_{\mathrm{i}}(1$, $60)=0.74, M S E=1,510.61, p>.10$.

The significant interaction between frequency and task type indicates that frequency effects were larger in the go/no-go naming task than in the lexical decision task. In addition, the significant three-way interaction further appears to reflect the fact that frequency interacted with script type in the go/no-go naming task, whereas frequency was additive with script type in the lexical decision task.

In the analyses of error rates, the main effect of frequency was significant both in the subject and the item analyses: $F_{s}(1,50)=114.88, M S E=79.12, p<.001 ; F_{i}(1,60)=$ $20.28, M S E=276.39, p<.001$. The main effect of task type was also significant in both analyses: $F_{\mathrm{s}}(1,50)=8.25$, $M S E=123.79, p<.01 ; F_{\mathrm{i}}(1,60)=10.71, M S E=58.56$, 
$p<.01$. The main effect of script type was marginally significant in the subject analysis, $F_{\mathrm{s}}(1,50)=3.50, M S E=$ $42.93, p<.07$, although nonsignificant in the item analysis, $F_{\mathrm{i}}(1,60)=0.34, M S E=276.39, p>.10$.

The interaction between frequency and task type was marginally significant in the subject analysis, $F_{s}(1,50)=$ $3.08, M S E=79.12, p<.09$, although it was nonsignificant in the item analysis, $F_{\mathrm{i}}(1,60)=2.52, M S E=58.56, p>$ .10. No other interactions were significant in either analysis (all $F \mathrm{~s}<1.8$ ).

\section{Discussion}

The central finding in Experiment 4 was the significant interaction between frequency and script type. Frequency effects were larger for Kanji words than for Katakana words. Also of note was that the frequency effects in Experiment 4 were larger than the frequency effects for the same stimuli in the lexical decision task (Experiment 1). Whereas these results are consistent with Balota and Chumbley's (1984) suggestion and our own (Hino \& Lupker, 1996) that frequency effects are primarily due to task-specific processes, they are not consistent with the predictions of Monsell et al.'s (1989) dual-route account.

\section{Experiment 5}

The main purpose of Experiment 5 was to examine an alternative explanation of the results of Experiment 4 . We have made the assumption that after having made the implicit decision that the character string is a word, participants do not ignore the established mental representations in favor of going back to reread the word. It is possible, however, that this assumption is incorrect. If it were-that is, if participants were carrying out all the preresponse components of a lexical decision task first and then going back and rereading the word in order to name it-then virtually any theory would predict that the frequency effect in go/no-go naming would essentially reflect the nature of the effects in both of the subtasks. Thus, virtually any theory that could account for our lexical decision and naming results could also account for the results of Experiment 4.

This explanation can be examined by rerunning Experiment 4 using masked targets. If the participants in Experiment 4 were making implicit lexical decisions and then rereading the words, masking the stimuli should prevent this behavior. Because of the unavailability of the visual stimulus, phonological coding would have to be based on memorial, rather than physical, representations. If the dualroute account is correct, an additive relationship between frequency and script type should now be observed (as it was in the lexical decision task). If, however, the effects in Experiment 4 were due to task-specific processes based on memorial representations, masking should have no effect, and the interaction between frequency and script type should once again be observed. To evaluate these possibilities, Experiment 5 was a go/no-go naming task with masked stimuli.

\section{Method}

Participants. Twenty-nine undergraduate students from Chukyo University participated in this experiment for course credit. All were native Japanese speakers and had normal or corrected-tonormal vision. None had participated in the previous experiments.

Stimuli. The stimuli were the same as those used in Experiments 1 and 4.

Procedure. The procedure was identical to that in Experiment 4 except that target stimuli were presented only for $300 \mathrm{~ms}$ and immediately replaced by a mask. The mask consisted of a row of number signs (\#\#\#) equal in length to the preceding target. The mask and a fixation point remained on the video monitor either until the participant responded or until $2 \mathrm{~s}$ had elapsed.

\section{Results}

There were 3 participants whose data were excluded from the analysis because they made too many errors (more than $20 \%$ ). Thus, the data from 26 participants were submitted to the analyses. A trial was considered a mechanical error if the participant's vocal response failed to trigger the voice key or some extraneous sound triggered the voice key. The mechanical errors were excluded from the data analyses. There were $5(0.13 \%$ of all trials) mechanical errors in total. For experimental word trials, response latencies less than 250 $\mathrm{ms}$ or greater than $1,500 \mathrm{~ms}$ were classified as errors and excluded from the latency analyses. Thus, 15 additional data points $(0.90 \%$ of the experimental word trials) were excluded in this fashion. Otherwise, the analyses were carried out in the same way as in Experiment 4 . The mean naming latencies and error rates from the subject analysis are presented in Table 6.

Word trials. In the analysis of response latencies, the main effect of frequency was significant both in the subject and the item analyses, $F_{s}(1,25)=259.77, M S E=2,191.92$, $p<.001, F_{\mathrm{i}}(1,60)=54.22, M S E=7,331.28, p<.001$, reflecting the fact that response latencies were faster for high-frequency words than for low-frequency words. The main effect of script type was also significant in both analyses, $F_{s}(1,25)=38.60, M S E=4,489.14, p<.001$; $F_{\mathrm{i}}(1,60)=14.73, M S E=7,331.28, p<.001$, reflecting the fact that response latencies were faster for Katakana words than for Kanji words. Most important, the interaction between frequency and script type was significant in the subject analysis, $F_{s}(1,25)=11.03, M S E=1,278.87, p<$

Table 6

Mean Response Latencies (in Milliseconds) and Error Rates in the Masked Go/No-Go Naming Task of Experiment 5

\begin{tabular}{lcccccc}
\hline & \multicolumn{4}{c}{ Word frequency } & \\
\cline { 2 - 5 } & \multicolumn{2}{c}{ Low } & & \multicolumn{2}{c}{ High } & \\
\cline { 2 - 4 } Script type & $M$ & Error (\%) & & $M$ & Error (\%) & RT difference \\
\hline Katakana & 726 & 18.99 & & 601 & 3.13 & 125 \\
Kanji & 831 & 33.46 & & 659 & 7.21 & 172 \\
\hline
\end{tabular}

Note. Mean error rates for Katakana nonwords and Kanji nonwords were $1.71 \%$ and $1.72 \%$, respectively. RT = reaction time. 
.01 , although not in the item analysis, $F_{\mathrm{i}}(1,60)=0.64$, $M S E=7,331.28$. Planned comparisons showed that the frequency effects were significant both for Kanji words, $t_{s}(25)=12.18, p<.001, t_{i}(30)=5.14, p<.001$, and for Katakana words, $t_{\mathrm{s}}(25)=14.98, p<.001, t_{\mathrm{i}}(30)=5.39$, $p<.001$. Thus, the interaction between frequency and script type was due to the fact that the frequency effect was greater for Kanji words than for Katakana words.

In the analyses of error rates, the main effect of frequency was significant in both analyses, $F_{s}(1,25)=95.61, M S E=$ $120.58, p<.001, F_{i}(1,60)=23.93, M S E=293.44, p<$ .001 , reflecting the fact that more errors were observed for low-frequency words than for high-frequency words. The main effect of script type was also significant in both analyses, $F_{\mathrm{s}}(1,25)=31.97, M S E=70.01, p<.001, F_{\mathrm{i}}(1$, $60)=4.59, M S E=293.44, p<.05$, reflecting the fact that responses were more accurate for Katakana words than for Kanji words. In addition, the interaction between frequency and script type was significant in the subject analysis, $F_{\mathrm{s}}(1$, 25) $=9.87, M S E=71.00, p<.01$, although not in the item analysis, $F_{\mathrm{i}}(1,60)=1.41, M S E=293.44, p>.10$, reflecting the fact that whereas error rates were greater for Kanji words than for Katakana words in the low-frequency condition, the difference was smaller in the high-frequency condition. As in Experiment 4, the majority of these errors (85\%) involved failures to respond rather than incorrect pronunciations.

Nonword trials. As in Experiment 4, the difference in error rates between Katakana and Kanji nonwords was not significant: $t_{s}(25)=.01 ; t_{i}(70)=.01$.

\section{Discussion}

Significant interactions between frequency and script type were observed for both naming latencies and error rates. Further, the effects of word frequency were quite similar to those in Experiment 4 (123 ms vs. $125 \mathrm{~ms}$ for Katakana words; $177 \mathrm{~ms}$ vs. $172 \mathrm{~ms}$ for Kanji words). Thus, the present results were essentially identical to those in Experiment 4, suggesting that the results of Experiment 4 were not due to participants rereading the words.

\section{Experiment 6}

Monsell et al.'s (1989) dual-route account appears to provide a quite viable explanation for the size difference in word frequency effects between lexical decision and naming tasks by assuming a frequency-insensitive sublexical coding process for retrieving phonology (Experiments 1 and 2). The results from the go/no-go naming task (Experiments 4 and 5), however, are problematic for this account because it has no obvious means of explaining the Frequency $\times$ Script Type interaction observed in that task. The idea is that because go/no-go naming requires participants to make an implicit lexical decision before pronouncing the words, lexical selection is generally required and, hence, the phonology used in the naming task should be that which is automatically available from the lexical route (see also Paap, McDonald, et al., 1987). As such, frequency effects should have been script independent, just as they were in the lexical decision task.

The key empirical focus then is the Frequency $\times$ Script Type interaction that appears in go/no-go naming (and standard naming) but not in lexical decision. Whereas a dual-route model would have trouble accounting for this difference, a task-specific explanation like that of Balota and Chumbley (1984) would not. That is, according to this type of explanation, the Frequency $\times$ Script Type interaction could arise during script-based phonological-coding processes that follow the implicit lexical decision process.

Before developing this argument further, however, one additional issue should be investigated. Certainly, as argued, one important difference between the go/no-go naming task and the lexical decision task is that the former requires a phonological-coding process, whereas the latter does not. Another difference, however, is that responses were required for only half the stimuli in the go/no-go naming task. This makes the comparison between tasks somewhat similar to the comparison between Donders's (1969) Type C and Type $B$ reactions. A criticism of this type of comparison was that the nature of the supposedly identical subprocesses may be different in the two situations. Although it is unclear exactly how this difference could have led to the different patterns of results in the two tasks, one cannot unambiguously conclude that the emergence of the interaction in the go/no-go naming task was unquestionably due to the phonological-coding process.

To address this issue, we designed Experiment 6 to be a go/no-go lexical decision task. ${ }^{6}$ As such, those subprocesses in this task that lead to a lexical decision should better parallel those in the go/no-go naming task than those same subprocesses in the standard lexical decision task did. No phonological coding would be required, however. Thus, if the Frequency $\times$ Script Type interaction in go/no-go naming is really due to the phonological-coding process and not to the fact that responses are only required to half the stimuli, the expectation is that this interaction should not emerge in Experiment 6.

\section{Method}

Participants. Twenty-seven undergraduate students from Chukyo University participated in this experiment. Each was paid a small amount of money for his or her participation. All were native Japanese speakers and had normal or corrected-to-normal vision. None had participated in the previous experiments.

Stimuli. The stimuli were the same as those used in Experiments 1,4 , and 5 .

Procedure. Participants were asked to press a key on a keyboard (using their dominant hand) only if the stimulus was a word. One of the two keys that flanked the space key was used as a response key. If a participant was right-handed, he or she was asked to press the key (XFER key) on the right of the space key on the keyboard. If a participant was left-handed, he or she was asked to press the key (NFER key) on the left of the space key. Otherwise the procedure was identical to that of Experiment 4.

\footnotetext{
${ }^{6}$ We would like to thank Derek Besner for suggesting this experiment.
} 


\section{Results}

Because there was a participant who made too many errors (more than 20\%), his data were excluded from the analyses. Thus, the data from 26 participants were submitted to the analyses. For the experimental word trials, response latencies less than $250 \mathrm{~ms}$ or greater than $1,500 \mathrm{~ms}$ were classified as errors and excluded from the latency analyses. Twenty-two data points from the experimental word trials $(1.32 \%)$ were thus excluded for falling outside the cutoffs. Otherwise, the analyses were carried out in the same way as in Experiment 4. The mean lexical decision latencies and error rates from the subject analysis are presented in Table 7.

Word trials. In the analysis of response latencies, the main effect of frequency was significant both in the subject and the item analyses, $F_{\mathrm{s}}(1,25)=197.05, M S E=3,482.27$, $p<.001, F_{\mathrm{i}}(1,60)=58.70, M S E=4,386.60, p<.001$, reflecting the fact that response latencies were faster for high-frequency words than for low-frequency words. The main effect of script type was significant in the subject analysis, $F_{\mathrm{s}}(1,25)=9.46, M S E=2,491.63, p<.01$, although not in the item analysis, $F_{\mathrm{i}}(1,60)=2.38, M S E=$ $4,386.60, p>.10$, reflecting the fact that response latencies were faster for Katakana words than for Kanji words. Most important, the interaction between frequency and script type was not significant in either analysis: $F_{\mathrm{s}}(1,25)=0.89$, $M S E=724.00 ; F_{\mathrm{i}}(1,60)=0.05, M S E=4,386.60$.

In the analyses of error rates, the main effect of frequency was significant in both analyses, $F_{8}(1,25)=50.06, M S E=$ $25.24, p<.001 ; F_{\mathrm{i}}(1,60)=7.29, M S E=106.61, p<.01$, reflecting the fact that responses to high-frequency words were more accurate than responses to low-frequency words. The main effect of script type was marginally significant in the subject analysis, $F_{s}(1,25)=4.09, M S E=23.50, p<$ .06 , but nonsignificant in the item analysis, $F_{\mathrm{i}}(1,60)=0.56$, $M S E=106.61$. The interaction between frequency and script type was not significant in either analysis, $F_{s}(1,25)=$ $0.00, M S E=24.22 ; F_{\mathrm{i}}(1,60)=0.00, M S E=106.61$.

Nonword trials. The error rates were $2.77 \%$ greater for Kanji nonwords than for Katakana nonwords. The difference was significant only in the subject analysis, $\mathrm{t}_{8}(25)=2.10$, $p<.05 ; t_{\mathrm{i}}(70)=1.19, p>.10$.

\section{Combined Analyses (With Lexical Decision Data From Experiment 1)}

To examine the task differences directly, we also carried out combined analyses with the experimental word trial data from Experiment 1. Subject and item ANOVAs based on response latencies and error rates from Experiments 1 and 6 were conducted based on a 2 (frequency: high vs. low) $\times 2$ (script type: Kanji vs. Katakana) $\times 2$ (task type: lexical decision task vs. go/no-go lexical decision task) design. In the subject analyses, frequency and script type were treated as within-subject factors, whereas task type was a betweensubjects factor. In the item analyses, frequency and script type were between-items factors, whereas task type was a within-item factor.
Table 7

Mean Response Latencies (in Milliseconds) and Error Rates in the Go/No-Go Lexical Decision Task of Experiment 6

\begin{tabular}{llccccc}
\hline & \multicolumn{4}{c}{ Word frequency } & \\
\cline { 2 - 5 } & \multicolumn{2}{c}{ Low } & & \multicolumn{2}{c}{ High } & \\
\cline { 2 - 5 } \cline { 5 - 6 } Script type & $M$ & Error (\%) & & $M$ & Eror (\%) & RT difference \\
\hline Katakana & 667 & 7.45 & & 509 & 0.48 & 158 \\
Kanji & 702 & 9.39 & & 534 & 2.40 & 168 \\
\hline
\end{tabular}

Note. Mean error rates for Katakana nonwords and Kanji nonwords were $7.27 \%$ and $10.04 \%$, respectively. $\mathrm{RT}=$ reaction time.

In the analyses of response latencies, the main effect of frequency was significant both in the subject and the item analyses: $F_{\mathrm{s}}(1,50)=311.28, M S E=3,037.18, p<.001$; $F_{\mathrm{i}}(1,60)=64.37, M S E=10,048.97, p<.001$. The main effect of script type was significant in the subject analysis, $F_{\mathrm{s}}(1,50)=22.76, M S E=2,119.96, p<.001$, and marginally significant in the item analysis, $F_{\mathrm{i}}(1,60)=3.57$, $M S E=10,048.97, p<.07$. The main effect of task type was not significant in either analysis: $F_{\mathrm{s}}(1,50)=0.00, M S E=$ $34,343.77 ; \mathrm{F}_{\mathrm{i}}(1,60)=0.15, M S E=1,352.18$.

The only interaction that was significant was the interaction between frequency and task type, $F_{s}(1,50)=13.06$, $M S E=3,037.18, p<.01 ; F_{\mathrm{i}}(1,60)=11.92, M S E=$ $1,352.18, p<.01$. (all other $F \mathrm{~s}<1$.) This interaction reflects the fact that frequency effects were greater in Experiment 6 than in Experiment 1.

In the analyses of error rates, the main effect of frequency was significant both in the subject and the item analyses: $F_{\mathrm{s}}(1,50)=131.76, M S E=49.31, p<.001 ; F_{\mathrm{i}}(1,60)=$ $14.95, M S E=267.43, p<.001$. The main effect of task type was also significant in both analyses: $F_{s}(1,50)=44.70$, $M S E=52.70, p<.001 ; F_{1}(1,60)=35.89, M S E=40.39$, $p<.001$. The main effect of script type was significant in the subject analysis, $F_{\mathrm{s}}(1,50)=4.08, M S E=36.06, p<.05$, although not in the item analysis, $F_{\mathrm{i}}(1,60)=0.34, M S E=$ 267.43 .

As in the latency analysis, the interaction between frequency and task type was significant in both analyses: $F_{8}(1$, $50)=18.66, M S E=49.31, p<.001 ; F_{i}(1,60)=14.02$, $M S E=40.39, p<.001$. No other effects, however, approached significance (all $F s<1$ ). In contrast to the results from the latency analysis, the significant Frequency $\times$ Task Type interaction reflects the fact that frequency effects for error rates were smaller in Experiment 6 than in Experiment 1.

\section{Discussion}

The main purpose of Experiment 6 was to evaluate the hypothesis that the Frequency $\times$ Script Type interaction observed in Experiments 4 and 5 was due to the nature of the subprocesses involved in making a lexical decision in go/no-go tasks. The lack of a Frequency $\times$ Script Type interaction in Experiment 6 indicates that the interaction 
observed in Experiments 4 and 5 was not due to the nature of those subprocesses. Rather, as argued earlier, this interaction, which arises only when participants must make a rapid naming response (i.e., in Experiments 2, 4, and 5), appears to be due to phonological-coding processes.

One other aspect of the results of Experiment 6 should be noted. The frequency effects in the latency data were significantly larger in this experiment than in the standard lexical decision task (i.e., Experiment 1). Further, the error rates, especially for the low-frequency words, were lower. If one adopts the position that the effects in Experiment 1 represent the full effect of frequency on lexical selection and that any postselection, decision-making processes are not frequency sensitive, this type of result would be difficult to explain. Thus, one must conclude either that (a) in the standard task, lexical decisions are often made without completing lexical selection, and thus the results of Experiment 1 underestimate the effects of frequency on the lexical-selection process, or (b) processes other than lexical selection (e.g., decision-making processes) are frequency sensitive and that these processes have a greater impact in a go/no-go task than in a standard task. A more complete discussion of the implications of these conclusions for the dual-route account (as well as for the other accounts) is presented in the next section.

\section{General Discussion}

Most models incorporating a lexicon are based on the idea of frequency-sensitive lexical units or a frequency-ordered serial search mechanism. Thus, frequency effects in word recognition are explained in terms of the time to select the appropriate lexical unit. Strict versions of these theories predict that the sizes of frequency effects should be the same in all word recognition tasks. As Balota and Chumbley $(1984,1985)$ have demonstrated, however, such is not the case. Further, on the basis of their own results, Balota and Chumbley (1984) have instead proposed that other, taskspecific processes, in particular, decision-making processes in the lexical decision task and pronunciation-related processes in the naming task, are the processes mainly responsible for frequency effects.

Using the framework provided by the dual-route model (Coltheart, 1978), Monsell et al. (1989) were able to present an alternative explanation of Balota and Chumbley's (1984) results that is entirely consistent with the basic premise of the original models. In particular, the reason that frequency effects in naming tasks are smaller than those in lexical decision is that, for regular words, participants need not complete lexical selection in order to produce a correct naming response. Rather, at least for low-frequency regular words, naming can be accomplished through a frequencyinsensitive assembly process. The result is that the naming of low-frequency regular words is more rapid, and thus the frequency effect is diminished.

In contrast, when exception words are named, lexical selection is required. For these words, their phonological codes are presumed to derive from processing on the lexical route. That is, lexical selection is first accomplished and it is followed by the automatic retrieval of the correct phonological code. Thus, for these words, the prediction is that frequency effects should be the same size in naming and lexical decision tasks. Monsell et al. (1989) demonstrated that such was the case for stress-final words in English, which, they argued, require lexical selection because of their irregular stress pattern.

As noted earlier, Monsell et al.'s (1989) overall pattern of results also presented a few problems for their interpretation. In particular, it was unclear why the frequency effect for stress-initial words was so much larger than that for stress-final words in lexical decision, given that the word sets were equated on frequency. More important, it was unclear why the frequency effects for the stress-initial and stress-final words in naming were so similar, given that stress-initial words supposedly are often named by the assembly route, whereas stress-final words are not. The purpose of the present experiments was to provide both a further examination of these issues as well as a new way of examining Monsell et al.'s account.

These goals were accomplished by using Japanese words written in either Kanji or Katakana script. Kanji is a logographic script with arbitrary spelling-to-sound correspondences. Thus, words written in Kanji are presumed to be named only by means of the lexical route (e.g., Wydell et al., 1995). Katakana, however, is a shallow script, and thus words written in Katakana can be named by using standard spelling-to-sound correspondences (i.e., the assembly route). The prediction that follows from Monsell et al.'s (1989) account is that for Kanji words, frequency effects should be the same size in the naming and lexical decision tasks because lexical selection is required in both situations. For Katakana words, the prediction is that the frequency effect should be smaller in naming than in lexical decision because these words, particularly the low-frequency words, are sometimes named by the frequency-insensitive assembly route. Finally, because Kanji and Katakana words were equated on frequency and familiarity, the prediction was that they would produce the same size-frequency effects in lexical decision. The results of Experiments 1 and 2 (reinforced by the results of Experiments 3 and 6 ) supported these predictions.

These results appear to provide compelling evidence for Monsell et al.'s (1989) account. As noted, however, the results are not inconsistent with other accounts. Thus, in Experiments 4 and 5, we used a new task, the go/no-go naming task, to provide a further test of Monsell et al.'s account. In this task, participants were presented with both words and nonwords; however, they were only required to name the words. As such, the presumption is that lexical selection is completed for all words. Because the assumption is that once lexical selection has been completed, the word's name is automatically available, then according to Monsell et al.'s account, the assembly route should play no role in the naming process. Thus, the results in go/no-go naming should parallel those in lexical decision. In particular, the frequency effects should be equivalent for Kanji and Katakana words. Such was not the case, however. As in the naming task, 
frequency effects were larger for Kanji words than for Katakana words.

\section{Phonological Code Retrieval in Go/No-Go Naming}

Dual-route account. This interaction between frequency and script type in go/no-go naming is therefore the central issue that must be dealt with if one wishes to preserve the account of frequency effects offered by the dual-route model. The interaction suggests that the naming process in go/no-go naming is script dependent, which should not be the case if the phonological codes used in the task were being retrieved from amodal lexical units. The question then is, can the dual-route framework be amended to explain this result?

As a first step, it appears to be necessary to assume that the phonological code that becomes available automatically when a lexical unit is accessed decays rapidly, and thus it would not be available at the precise time that a word decision is reached in a go/no-go naming task. Thus, the code that is used in this task must be regenerated after the participant has decided that the character string is, in fact, a word (see Forster \& Davis, 1991, for a similar argument). One could even propose that this regeneration process is frequency sensitive, which would account for the finding that the frequency effects were larger in go/no-go naming than in lexical decision.

Unfortunately, even if this assumption is correct (and, as we argue below, we believe it is), the central issue-the interaction between frequency and script type-remains unexplained. The prediction from the dual-route account would still be that the phonological codes were being regenerated on the basis of amodal lexical representations, and thus there is no reason that the frequency effect would be smaller for Katakana words than for Kanji words.

If a second assumption is added, however, the dual-route account, at least in theory, may be able to explain the interaction between frequency and script type. That assumption is that, because of the time relations between the routes, the assembly route does contribute to naming low-frequency Katakana words in the go/no-go naming task. The idea is that, for high-frequency words, the code from the assembly route would become available after the point at which readers had regenerated a phonological code from the lexical unit. Thus, the code from the assembly route would be of little use when readers are naming high-frequency words. For low-frequency Katakana words, however, because their lexical processing takes somewhat longer, the code from the assembly route could become available before readers had regenerated the code from the lexical unit. If so, the regeneration process could be short-circuited, and a relatively rapid response could be produced. Such, of course, could not occur for low-frequency Kanji words because the assembly route would not provide a correct code for those words. The result would be a smaller frequency effect for Katakana words than for Kanji words, as we had observed.?

Stated more concretely, the go/no-go naming task requires a lexical-selection process (which is frequency sensitive), a decision process (which is not, according to the lexical- selection/dual-route account), and then, because the code made available initially has decayed, a code regeneration process (which may also be frequency sensitive). Further, we must also assume that for high-frequency Katakana words, these processes are virtually completed at the point when the assembly route produces a phonological code, whereas for low-frequency Katakana words, the processes are still ongoing.

The question that this second assumption raises, however, is whether it would be possible to get these time relations right so that the model could also account for the results in the standard naming task. That is, the essence of this assumption is that the assembly route does not provide a phonological code until processing of the high-frequency words in the go/no-go naming task (i.e., lexical selection, decision, and code regeneration) is nearing or at completion. This implies that the assembly route is rather slow. In standard naming, the fact that there is a reduced frequency effect for Katakana words is taken to mean that, for low-frequency words, the assembly route provides a phonological code before the lexical route does on a reasonable proportion of trials. This implies that the assembly route is rather fast. Without actually modeling these processes, it is unclear that this apparent paradox is resolvable. Thus, at present it seems wise to consider alternate explanations.

Alternate explanations. First, it appears that any explanation of the present data must incorporate the assumption that participants regenerate the code that they use in go/no-go naming rather than use one that had become available automatically. If participants were using codes that became available automatically, those codes should have been ready by the time that the implicit lexical decision had been made (e.g., in dual-route terms, the lexical route should certainly have provided a code by that time, even if the assembly route had not). Thus, there would be no reason for there to be a Script Type $\times$ Frequency interaction in go/no-go naming. That is, as indicated by the results of Experiments 1 and 6, the process of making a lexical decision itself does not produce a Script Type $\times$ Frequency interaction. Thus, this interaction must have been due to an extra, frequency-sensitive, code regeneration process.

Second, the Frequency $\times$ Script Type interaction suggests that the representations driving code regeneration in the go/no-go naming task are not amodal lexical units but are instead script-dependent units. That is, they would be units that, to a large degree, represent the orthographic character of the presented words. As such, the code regeneration process would follow a path that is somewhat similar to that followed by the initial code generation process in a standard naming task. Thus, the Frequency $\times$ Script Type interaction would arise for essentially the same reasons in those two tasks.

The conclusion that the regeneration process is being driven by script-dependent units, however, raises an additional question. Why would these units take over a role that would seem to be more appropriately handled by lexical

\footnotetext{
${ }^{7}$ We would like to thank Ken Forster for bringing this alternative explanation to our attention.
} 
units? The amodal lexical units are, presumably, both more stable than representations based on orthographic characteristics and have been more recently activated when participants are attempting to regenerate a phonological code in a go/no-go naming task. Thus, the expectation is that retrieval from lexical units should be easier than retrieval from script-dependent units in a go/no-go naming task.

One way to answer to this question is to suggest that the codes originally produced by the lexical route, if not used immediately, are suppressed. Thus, it may be extremely difficult to regenerate the code from a lexical unit. If so, it may actually be easier for the orthographic units to drive the reactivation process, just as they drive the original lexical activation process in standard naming.

For this alternative to work, however, it has to be further assumed that orthographic units maintain their activation for long enough to be reused. This assumption may be somewhat problematic. The role of orthographic units in models postulating a lexicon is to enable selection of a more stable lexical unit. Thus, there would be no obvious reason why the activation of orthographic units would be maintained after a lexical unit had been selected and through whatever decisionmaking processes that might follow.

A second way to answer the question is to argue that, in Japanese, the lexical units themselves are script dependent. As noted, although it is possible to write most Japanese words either in Kanji, Katakana, or Hiragana, any particular word is normally written in one script only. Thus, it is possible that lexical units for words always written in a logographic script like Kanji may be slightly different from lexical units for words always written in a shallow script like Katakana. If so, it is also possible that the code regeneration process, although driven by lexical units, could maintain the characteristics of a code generation process that was driven by orthographic units (i.e., it could produce the Frequency $\times$ Script Type interaction).

This alternative is also problematic, however, because it fails to account for a similar result in go/no-go naming in which English words are used. That is, as discussed, Kanji words are like exception words in English in that they cannot be named accurately by applying spelling-to-sound rules, whereas Katakana words are like regular words in English in that they can be named accurately by applying spelling-tosound rules. The result is that in both languages, the frequency effect in naming is smaller for the words that can be named by applying spelling-to-sound rules, but the frequency effect in lexical decision is equivalent for the two word types. What is also true, however, is that, in English, just as in Japanese, the frequency effect in go/no-go naming is smaller for the words that can be named by applying spelling-to-sound rules (i.e., the regular words) than for the words that cannot (i.e., the exception words; Hino \& Lupker, 1998; Kinoshita \& Wollams, 1998). That is, there is also a Frequency $\times$ Regularity interaction in go/no-go naming in English.

The implication of this parallel is that these effects in go/no-go naming in the two languages most likely have the same locus. If so, this particular alternative explanation of the Frequency $\times$ Script Type interaction in Japanese would be rather problematic because it would make no sense when applied to English. That is, although there may be differences between Kanji words and Katakana words at the lexical level because of the differences in visual format, there cannot be a parallel difference between regular words and exception words in English because they do not have different visual formats. The point should also be made that a general conclusion from past research is that lexical representations in English are insensitive to visual formats in any case (e.g., Besner, 1983; Besner \& McCann, 1987; Evett \& Humphreys, 1981; Paap, Newsome, \& Noel, 1984; Rayner, McConkie, \& Zola, 1980). Thus, if regeneration were done just from the lexical units in English in a go/no-go naming task, no Frequency $\times$ Regularity interaction would be expected.

A third way to answer this question, and one that seems more consistent with the present data, is to assume, as assumed by most parallel-distributed-processing models (c.g., Plaut \& McClelland, 1993; Plaut et al., 1996; Seidenberg, 1992; Seidenberg \& McClelland, 1989; Van Orden, Pennington, \& Stone, 1990), that lexical units simply do not exist and therefore that orthographic units play a more central role in word recognition. In particular, the assumption would be the that these units drive both the original generation of phonological codes in standard naming and the regeneration of phonological codes in go/no-go naming. Thus, the patterns that emerged in a standard naming task would be expected to emerge in go/no-go naming as well. Note, of course, that this assumption is not particularly compatible with the dual-route account.

Although these types of models have not yet been applied to naming in Japanese, it seems likely that they would be able to capture the basic patterns reported here. In essence, the basis of these models is that the weights on connections from orthographic to phonological units are stronger for words with consistent mappings from orthography to phonology than for words with inconsistent mappings. As a consequence, consistent words would be named faster than inconsistent words (e.g., as with the regularity effect in English). Further, because these differences in the strength of connections would have more impact in naming lowfrequency words than in naming high-frequency words, frequency effects would be greater for words with inconsistent orthography-to-phonology correspondences. Thus, the larger frequency effects for generally inconsistent Kanji words than for consistent Katakana words in both standard and go/no-go naming would seem to be easily accounted for within this type of framework. What might be more of a puzzle, however, would be (a) how this type of model would explain the lack of consistency effects in Kanji word naming reported by Wydell et al. (1995) ${ }^{8}$ and (b) why the frequency

\footnotetext{
${ }^{8}$ Contrary to Wydell et al. (1995), Hue (1992) has observed the effects of regularity and consistency in Chinese character naming. In addition, Wydell, Butterworth, Shibahara, and Zorzi (1997) and Fushimi, ljuin, and Tatsumi (1996) have recently reported a significant difference in naming latencies for regular-consistent versus irregular-inconsistent Kanji words (i.e., words in which the inconsistent character involved the lower frequency pronunciation). Thus, it is not entirely clear whether character-to-sound regularity-consistency affects Kanji word naming or not.
} 
effect for Katakana words in the naming task (Experiment 2) was as large as it was given that the spelling-to-sound correspondences for those words are completely consistent (see Plaut et al., 1996; Seidenberg, 1992)..$^{9}$

If this third answer is correct, of course, it implies that the conventional explanation of frequency effects as reflecting lexical-selection time is incorrect. Lexical selection cannot be the locus of frequency effects if there are no lexical units to select among. It should be noted, however, that there is considerable controversy about the ability of these types of models to explain word recognition performance, even in English (e.g., Besner, in press; Besner et al., 1990; Coltheart et al., 1993; Fera \& Besner, 1992). In particular, the points made by Besner et al. about the inability of these models to explain lexical decision data are quite well-taken. As Plaut et al. (1996) suggested, however, this type of model may be much more successful in explaining lexical decision results when a semantic system is fully implemented. At present, then, there is no clear answer as to how well the models will be able to respond to that specific challenge. Nonetheless, the early successes of these types of models at least suggest the possibility that the naming process could be modeled without postulating lexical units.

\section{The Locus of Frequency Effects in the Lexical Decision Task}

Let us consider again the general question of the extent to which frequency effects in lexical decision tasks are lexicalselection effects. First, it seems unlikely that an account of lexical decision performance based solely on the lexicalselection process can satisfactorily account for the myriad effects observed in lexical decision tasks. For example, as Grainger and Jacobs (1996) have described, lexical decision performance is sensitive to a number of orthographic structure variables (e.g., neighborhood size, the frequency of orthographic neighbors, etc.; see also Andrews, 1989, 1992; Forster \& Shen, 1996; Sears, Hino, \& Lupker, 1995). Further, performance is also sensitive to semantic factors such as concreteness (James, 1975), polysemy (Hino \& Lupker, 1996; Jastrzembski, 1981; Millis \& Button, 1989; Rubenstein et al., 1970; Rubenstein, Lewis, \& Rubenstein, 1971), and the nature of the semantic context (e.g., see Neely, 1991, for a through review of the semantic priming literature). On the basis of such results, a consensus has emerged (e.g., Coltheart, Davelaar, Jonasson, \& Besner, 1977; Forster, 1981; Forster \& Shen, 1996; Grainger \& Jacobs, 1996; Hino \& Lupker, 1996) that lexical decision performance is driven by much more than the lexicalselection process. In particular, even models in which lexical selection plays a major role have also come to incorporate things such as flexible activation criteria and time deadlines as well as a decision process in order to explain many of those types of effects (see also Coltheart et al., 1993).

When lexical-selection models make these concessions, the main contention between Balota and Chumbley's (1984) position and Monsell et al.'s (1989) position becomes whether the decision process is a process that is really part of the normal lexical-selection process (a possibility suggested by Monsell et al.) or whether it is a process implemented essentially for the purposes of making lexical decisions. If it is the latter, the nature and size of frequency effects in lexical decision tasks may tell us very little about the role of frequency in normal reading.

More recently, Balota (1990) presented the following arguments to support Balota and Chumbley's (1984) position that the decision-making process is implemented essentially for purposes of making lexical decisions and that it is a major contributor to the frequency effects in lexical decision tasks. First, because a binary decision task such as the lexical decision task necessarily requires a decision-making process, if there is a possibility that the decision-making process is frequency sensitive, it is impossible to attribute frequency effects in the lexical decision task solely to the lexicalselection process. Second, evidence that the decisionmaking process is frequency sensitive comes from the fact that the sizes of frequency effects are modulated by the nature of nonwords (e.g., James, 1975; Shulman \& Davison, 1977; Shulman et al., 1978; Stone \& Van Orden, 1993). In particular, with wordlike nonwords (i.e., pseudohomophones), it becomes more difficult to discriminate lowfrequency words from nonwords, and thus frequency effects increase. When nonwords are less wordlike (i.e., unpronounceable nonwords), however, it becomes easier to discriminate low-frequency words from nonwords, and thus frequency effects decrease.

As noted earlier, however, this particular modulation of frequency effects due to the nonword types can also be explained by lexical-selection models. With less wordlike nonwords, lexical decisions can, in theory, be made without isolating a unique lexical unit (i.e., they can be made on the basis of orthographic properties or overall initial lexical activity), leading to a decrease in frequency effects. However, if an extra, frequency-sensitive spell-checking process is required because the nonwords are pseudohomophones, frequency effects may increase. Thus, further evidence supporting Balota and Chumbley's (1984) position is required.

Some additional support for this claim is provided by contrasting Experiments 1 and 6. In both instances, participants were asked upon to decide whether a character string is a word. The processing in both instances would involve selecting the appropriate lexical unit and completing whatever decision-making processes were necessary to verify that it is the appropriate unit. From the perspective of a lexical-selection account of frequency effects, frequency should affect the first of these processes but not the second, meaning that the frequency effects should be the same size in the two tasks. The fact that they were not the same size is somewhat problematic for this account.

\footnotetext{
${ }^{9}$ Although the character-to-sound correspondences are quite consistent for Kana words, the orthographies of these words contain no information indicating accent patterns. Thus, there may be ambiguities in accent for Kana-written words, ambiguities that must be resolved by consulting lexical information. If so, the process of resolving these ambiguities may increase the sizes of frequency effects in naming tasks.
} 
As suggested earlier, the implication is that in the standard task, either (a) lexical decisions must at times be made without completing lexical selection and thus the results of Experiment 1 underestimate the effects of frequency on the lexical-selection process, or (b) that processes subsequent to lexical selection (e.g., decision-making processes) are frequency sensitive and that these processes have a greater impact in a go/no-go task than in the standard task.

The first of these explanations would not necessarily be inconsistent with Monsell et al.'s (1989) dual-route account. It would, however, be inconsistent with the analysis of the results of previous experiments provided by that account. That is, naming Kanji words presumably requires lexical selection. Thus, the results of the naming task (Experiment 2) appear to set an approximate upper bound on the size of the frequency effect attributable to the lexical-selection process for Kanji words. This upper bound value $(94 \mathrm{~ms})$ was approximately the same size as the corresponding effect in the lexical decision task $(110 \mathrm{~ms})$, thus providing converging evidence that the two tasks were both giving reasonable estimates of the size of the frequency effect that should be attributed to the lexical-selection process. Thus, to now argue that the $(110 \mathrm{~ms})$ effect in Experiment 1 underestimated the impact of frequency on lexical selection would be to argue against this earlier established position. Further, it would, of course, raise the question of why the frequency effect in naming for Kanji words (words that presumably require lexical selection in order to be named) was not larger than the frequency effect in the standard lexical decision task of Experiment 1.

The second of these explanations, in essence, amounts to adopting Balota and Chumbley's (1984) basic position. Note also that this idea is consistent with expectations based on a task analysis. In standard lexical decision tasks, there is pressure to make a rapid response to all stimuli. Thus, when an unfamiliar low-frequency word is encountered, there would be a strong push to decide that the stimulus is a nonword, allowing one to make a reasonably rapid nonword response. The result is that trials involving unfamiliar low-frequency words end up counting as errors and not contributing to the mean latency for low-frequency words.

In a go/no-go task, however, nonwords do not require a response. Thus, when an unfamiliar low-frequency word is encountered (i.e., a word that is so unfamiliar that it seems to be a nonword), although a participant might have sufficient information to reach a negative decision, a trial-terminating, negative response would not be made. Thus, preresponse processing can continue. If so, and if the word actually is in the individual's vocabulary, ultimately the participant will come to realize that the stimulus is a word. If this realization does not come too late for the participant to respond before the upper latency cutoff has been reached, the result will be a reasonably long latency rather than an error. Thus, error rates would decrease, but mean latency for low-frequency words would increase, increasing the size of the frequency effect. As such, it would appear that the difference between the standard and go/no-go lexical decision tasks could be explained by adopting this second explanation.

A further conclusion that seems to follow from these results (regardless of which assumption was adopted) would be that even if the lexical-selection process itself does play some role in making lexical decisions, that role must be quite minor, particularly for low-frequency words. The reason is that because only words have lexical units, a successful lexical selection should allow an accurate decision to be made. If we assume that lexical selection for low-frequency words was typically being successfully completed by the time responding was accomplished in the standard task, there would be no reason to prolong processing in the go/no-go lexical decision task. Thus, the frequency effects should be approximately the same size in the two tasks. The only explanation for the larger frequency effects in go/no-go lexical decision is that participants do not treat a successful lexical selection as diagnostic of the letter string's being a word. If, however, we assume that lexical selection for low-frequency words had often not been completed by the time responding was accomplished in the standard task, this implies that participants tend to make their lexical decisions in that task on other bases. Thus, either way, the implication is that successfully locating an appropriate lexical unit is not particularly important in the process of making lexical decisions.

\section{Conclusions}

The purpose of the present article was to examine a version of the dual-route model (Monsell et al., 1989) that had had some success accounting for performance in word recognition tasks. This model is also one that can serve as a representative of a class of models, that is, those that incorporate a lexicon and a lexical-selection process as the locus of frequency effects. Although this account accurately predicted the results from Experiments 1 and 2, its inability to accurately predict performance in go/no-go tasks without either making tenuous assumptions or giving up some of its basic principles raises strong doubts about its viability.

Data from the go/no-go experiments instead suggest that the lexical-selection process, if it exists at all, really plays very little role in producing frequency effects. Instead, it appears that in naming tasks, frequency effects seem to be due mainly to task-specific, phonological-coding processes, whereas in lexical decision tasks, frequency effects seem mainly to be due to task-specific, decision-making processes. That is, on the whole, we take these data to be more supportive of the position of Balota and Chumbley (1984), a position that is consistent with our earlier stated position (Hino \& Lupker, 1996) as well as being reasonably consistent with the positions offered by a number of other researchers (e.g., Besner, 1983; Besner \& McCann, 1987; Carr, Pollatsek, \& Posner, 1981; Carr, Posner, Pollatsek, \& Snyder, 1979; McCann \& Besner, 1987).

\section{References}

Anderson, J. R., \& Reder, L. M. (1974). Negative judgments in and about semantic memory. Journal of Verbal Learning and Verbal Behavior, 13, 664-681.

Andrews, S. (1989). Frequency and neighborhood effects on 
lexical access: Activation or search? Journal of Experimental Psychology: Learning, Memory, and Cognition, 15, 802-814.

Andrews, S. (1992). Frequency and neighborhood effects on lexical access: Lexical similarity or orthographic redundancy? Journal of Experimental Psychology: Leaming, Memory, and Cognition, 18, 234-254.

Balota, D. A. (1990). The role of meaning in word recognition. In D. A. Balota, G. B. Flores d'Arcais, \& K. Rayner (Eds.), Comprehension processes in reading (pp. 9-32). Hillsdale, NJ: Erlbaum.

Balota, D. A., \& Chumbley, J. I. (1984). Are lexical decisions a good measure of lexical access? The role of word frequency in the neglected decision stage. Journal of Experimental Psychology: Human Perception and Performance, 10, 340-357.

Balota, D. A., \& Chumbley, J. I. (1985). The locus of wordfrequency effects in the pronunciation task: Lexical access and/or production? Journal of Memory and Language, 24, 89-106.

Balota, D. A., \& Chumbley, J. I. (1990). Where are the effects of frequency in visual word recognition tasks? Right where we said they were! Comment on Monsell, Doyle, and Haggard (1989). Journal of Experimental Psychology: General, 119, 231-237.

Becker, C. A. (1980). Semantic context effects in visual word recognition: An analysis of semantic strategies. Memory \& Cognition, 8, 493-512.

Besner, D. (1983). Basic decoding components in reading: Two dissociable feature extraction processes. Canadian Journal of Psychology, 37, 429-438.

Besner, D. (in press). Basic processes in reading: Multiple routines in localist and connectionist models. In R. M. Klein \& P. A. McMullen (Eds.), Converging methods for understanding reading and dyslexia. Cambridge, MA: MIT Press.

Besner, D., \& Hildebrandt, N. (1987). Orthographic and phonological codes in the oral reading of Japanese kana. Journal of Experimental Psychology: Learning, Memory, and Cognition, 13, 335-343.

Besner, D., \& McCann, R. S. (1987). Word frequency and pattern distortion in visual word identification and production: An examination of four classes of models. In M. Coltheart (Ed.), Attention and performance XII: The psychology of reading (pp. 201-219). Hillsdale, NJ: Erlbaum.

Besner, D., \& Smith, M. C. (1992). Basic processes in reading: Is the orthographic depth hypothesis sinking? In R. Frost \& L. Katz (Eds.), Orthography, phonology, morphology, and meaning (pp. 45-66). Amsterdam: North-Holland.

Besner, D., Twilley, L., McCann, R. S., \& Seergobin, K. (1990). On the association between connectionism and data: Are a few words necessary? Psychological Review, 97, 432-446.

Brown, P., Lupker, S. J., \& Colombo, L. (1994). Interacting sources of information in word naming: A study of individual differences. Joumal of Experimental Psychology: Human Perception and Performance, 20, 537-554.

Buchanan, L., \& Besner, D. (1993). Reading aloud: Evidence for the use of a whole word nonsemantic pathway. Canadian Journal of Experimental Psychology, 47, 133-152.

Carr, T. H., Pollatsek, A., \& Posner, M. I. (1981). What does the visual system know about words? Perception \& Psychophysics, 29, 183-190.

Carr, T. H., Posner, M. I., Pollatsek, A., \& Snyder, C. R. R. (1979). Orthography and familiarity effects in word processing. Journal of Experimental Psychology: General, 108, 389-414.

Clark, H. H. (1973). The language-as-fixed-effect fallacy: A critique of language statistics in psychological research. Journal of Verbal Learning and Verbal Behavior, 12, 335-359.
Cohen, J. (1976). Random means random. Journal of Verbal Learning and Verbal Behavior, 15, 261-262.

Coltheart, M. (1978). Lexical access in simple reading tasks. In G. Underwood (Ed.), Strategies of information processing (pp. 151-216). London: Academic Press.

Coltheart, M., Curtis, B., Atkins, P., \& Haller, M. (1993). Models of reading aloud: Dual-route and parallel-distributed-processing approaches. Psychological Review, 100, 589-608.

Coltheart, M., Davelaar, E., Jonasson, J. T., \& Besner, D. (1977). Access to the internal lexicon. In S. Dornic (Ed.), Attention and performance VI (pp. 535-555). New York: Academic Press.

Donders, F. C. (1969). On the speed of mental processes. In G. Koster (Ed.), Attention and performance II: Acta Psychologica, $30,412-431$.

Evett, L. J., \& Humphreys, G. W. (1981). The use of abstract graphemic information in lexical access. Quarterly Journal of Experimental Psychology: Human Experimental Psychology, 33A, 325-350.

Fera, P., \& Besner, D. (1992). The process of lexical decision: More words about a parallel disributed processing model. Journal of Experimental Psychology: Learning, Memory, and Cognition, 18, 749-764.

Forster, K. I. (1976). Accessing the mental lexicon. In R. J. Wales \& E. Walk (Eds.), New approaches to language mechanisms (pp. 257-287). Amsterdam: North-Holland.

Forster, K. I. (1981). Priming and the effects of sentence and lexical contexts on naming time: Evidence for autonomous lexical processing. Quarterly Joumal of Experimental Psychology: Human Experimental Psychology, 33A(4), 465-495.

Forster, K. I., \& Chambers, S. M. (1973). Lexical access and naming time. Journal of Verbal Learning and Verbal Behavior, $12,627-635$.

Forster, K. I., \& Davis, C. (1991). The density constraint on form-priming in the naming task: Interference effects from a masked prime. Journal of Memory and Language, 30, 1-25.

Forster, K. I., \& Shen, D. (1996). No enemies in the neighborhood: Absence of inhibitory neighborhood effects in lexical decision and semantic categorization. Journal of Experimental Psychology: Learning, Memory, and Cognition, 22, 696-713.

Fushimi, T., Ijuin, M., \& Tatsumi, I. F. (1996, September). Kanji-Jukugo no ondoku ni okeru consistency-kouka (1) [Consistency effects in the naming of Kanji words]. Paper presented at the 60th Annual Meeting of the Japanese Psychological Association, Tokyo, Japan.

Grainger, J., \& Jacobs, A. M. (1996). Orthographic processing in visual word recognition: A multiple read-out model. Psychological Review, 103, 518-565.

Hino, Y., \& Lupker, S. J. (1996). The effects of polysemy in lexical decision and naming: An alternative to lexical access accounts. Journal of Experimental Psychology: Human Perception and Performance, 22, 1331-1356.

Hino, Y., \& Lupker, S. J. (1998). The effects of word frequency and spelling-to-sound regularity in naming with and without preceding lexical decision. Manuscript submitted for publication.

Hue, C. W. (1992). Recognition processes in character naming. In H. C. Chen \& O. J. Tzeng (Eds.), Language processing in Chinese (pp. 93-107). Amsterdam: North-Holland.

James, C. T. (1975). The role of semantic information in lexical decisions. Journal of Experimental Psychology: Human Perception and Performance, 1, 130-136.

Jastrzembski, J. E. (1981). Multiple meanings, number of related meanings, frequency of occurrence, and the lexicon. Cognitive Psychology, 13, 278-305.

Keppel, G. (1976). Words as random variables. Journal of Verbal Learning and Verbal Behavior, 15, 263-265. 
Kinoshita, S., \& Wollams, A. M. (1998). The left-to-right regularity effect and strategy effects in naming. Manuscript submitted for publication.

McCann, R. S., \& Besner, D. (1987). Reading pseudohomophones: Implications for models of pronunciation assembly and the locus of word-frequency effects in naming. Journal of Experimental Psychology: Human Perception and Performance, 13, 14-24.

McClelland, J. L., \& Rumelhart, D. E. (1981). An interactive activation model of context effects in letter perception: Part 1. An account of basic findings. Psychological Review, 88, 375407.

Millis, M. L., \& Button, S. B. (1989). The effect of polysemy on lexical decision time: Now you see it, now you don't. Memory \& Cognition, 17, 141-147.

Milward, R. B., Rice, G., \& Corbett, A. (1975). Category production measures and verification times. In R. A. Kennedy \& R. W. Wiles (Eds.), Studies in long-term memory (pp. 219-252). New York: Wiley.

Monsell, S. (1990). Frequency effects in lexical tasks: Reply to Balota and Chumbley. Journal of Experimental Psychology: General, 119, 335-339.

Monsell, S. (1991). The nature and locus of word frequency effects in reading. In D. Besner \& G. W. Humphreys (Eds.), Basic processes in reading: Visual word recognition (pp. 148-197). Hillsdale, NJ: Erlbaum.

Monsell, S., Doyle, M. C., \& Haggard, P. N. (1989). Effects of frequency on visual word recognition tasks: Where are they? Journal of Experimental Psychology: General, 118, 43-71.

Morton, J. (1969). Interaction of information in word recognition. Psychological Review, 76, 165-178.

Morton, J., \& Sasanuma, S. (1984). Lexical access in Japanese. In L. Henderson (Ed.), Orthographies and reading: Perspectives from cognitive psychology, neuropsychology and linguistics (pp. 25-42). London: Erlbaum.

National Language Research Institute. (1963). Gendai-zasshi 90 shu no yougo youji: Dai2 bunsatsu, Kanji-hyou [Vocabulary and Chinese characters in ninety magazines of today: Vol. 2. Chinese characters frequency tables]. Tokyo: Shuei Shuppan.

National Language Research Institute. (1970). Denshikeisanki niyoru shimbun no goi-chosa [Studies on the vocabulary of modern newspapers: Vol. 1. General descriptions and vocabulary frequency tables]. Tokyo: Shuei Shuppan.

Neely, J. H. (1991). Semantic priming effects in visual word recognition: A selective review of current findings and theories. In D. Besner \& G. W. Humphreys (Eds.), Basic processes in reading: Visual word recognition (pp. 264-336). Hillsdale, NJ: Erlbaum.

Ogawa, T., Nishida, T., \& Akatsuka, T. (1977). Shinjigen [New origins of characters]. Tokyo: Kadokawa Shoten.

Paap, K. R., Chen, L., \& Noel, R. W. (1987, November). Word recognition: Is the sky falling on top-down processing? $\mathrm{Pa}-$ per presented at the meeting of the Psychonomic Society, Seattle, WA.

Paap, K. R., McDonald, J. E., Schvaneveldt, R. W., \& Noel, R. W. (1987). Frequency and pronounceability in visually presented naming and lexical decision tasks. In M. Coltheart (Ed.), Attention and performance XII: The psychology of reading (pp. 221-243). Hillsdale, NJ: Erlbaum.

Paap, K. R., Newsome, S. L., McDonald, J. E., \& Schvaneveldt, R. W. (1982). An activation-verification model for letter and word recognition: The word-superionity effect. Psychological Review, 89, 573-594.

Paap, K. R., Newsome, S. L., \& Noel, R. W. (1984). Word shape's in poor shape for the race to the lexicon. Joumal of Experimental
Psychology: Human Perception and Performance, 10, 413428.

Paap, K. R., \& Noel, R. W. (1991). Dual-route models of print to sound: Still a good horse race. Psychological Research, 53, 13-24.

Patterson, K., \& Coltheart, M. (1987). Phonological processes in reading: A tutorial review. In $\mathbf{M}$. Coltheart (Ed.), Attention and performance XII: The psychology of reading (pp. 421-447). Hillsdale, NJ: Erlbaum.

Plaut, D. C., \& McClelland, J. L. (1993). Generalization with componential attractors: Word and nonword reading in an attractor network. Proceedings of the 15th Annual Conference of the Cognitive Science Society (pp. 824-829). Hillsdale, NJ: Erlbaum.

Plaut, D. C., McClelland, J. L., Seidenberg, M. S., \& Patterson, K. (1996). Understanding normal and impaired word reading: Computational principles in quasi-regular domains. Psychological Review, 103, 56-115.

Rayner, K., McConkie, G. W., \& Zola, D. (1980). Integrating information across eye movements. Cognitive Psychology, 12, 206-226.

Rubenstein, H., Garfield, L., \& Millikan, J. A. (1970). Homographic entries in the internal lexicon. Journal of Verbal Learning and Verbal Behavior, 9, 487-494.

Rubenstein, H., Lewis, S. S., \& Rubenstein, M. A. (1971). Homographic entries in the internal lexicon: Effects of systematicity and relative frequency of meanings. Journal of Verbal Learning and Verbal Behavior, 10, 57-62.

Rumelhart, D. E., \& McClelland, J. L. (1982). An interactive activation model of context effects in letter perception: Part 2. The contextual enhancement effect and some tests and extensions of the model. Psychological Review, 89, 60-94.

Sears, C. R., Hino, Y., \& Lupker, S. J. (1995). Neighborhood size and neighborhood frequency effects in word recognition. Journal of Experimental Psychology: Human Perception and Performance, 21, 876-900.

Seidenberg, M. S. (1992). Beyond orthographic depth in reading: Equitable division of labor. In R. Frost \& L. Katz (Eds.), Orthography, phonology, morphology, and meaning (pp. 85118). Amsterdam: North-Holland.

Seidenberg, M. S., \& McClelland, J. L. (1989). A distributed, developmental model of word recognition and naming. Psychological Review, 96, 521-568.

Seidenberg, M. S., Waters, G. S., Barnes, M. A., \& Tanenhaus, M. K. (1984). When does irregular spelling or pronunciation influence word recognition? Joumal of Verbal Learning and Verbal Behavior, 23, 383-404.

Shulman, H. G., \& Davison, T. C. B. (1977). Control properties of semantic coding in a lexical decision task. Journal of Verbal Learning and Verbal Behavior, 16, 91-98.

Shulman, H. G., Hornak, R., \& Sanders, E. (1978). The effect of graphemic, phonemic, and semantic relationships on access to lexical structures, Memory \& Cognition, 6, 115-123.

Smith, J. E. K. (1976). The assuming-will-make-it-so fallacy. Journal of Verbal Learning and Verbal Behavior, 15, 262-263.

Stone, G. O., \& Van Orden, G. C. (1993). Strategic control of processing in word recognition. Journal of Experimental Psychology: Human Perception and Performance, 19, 744-774.

Theios, J., \& Muise, J. G. (1977). The word identification process in reading. In N. J. Castellan, D. B. Pisoni, \& G. R. Potts (Eds.), Cognitive theory (Vol. 2, pp. 289-321). Hillsdale, NJ: Erlbaum.

Van Orden, G. C., Pennington, B. F., \& Stone, G. O. (1990). Word identification in reading and promise of subsymbolic psycholinguistics. Psychological Review, 97, 488-522. 
Waters, G. S., \& Seidenberg, M. S. (1985). Spelling-sound effects in reading: Time-course and decision criteria. Memory \& Cognition, 13, 557-572.

Wike, E. L., \& Church, J. D. (1976). Comments on Clark's "The language-as-fixed-effect fallacy." Journal of Verbal Learning and Verbal Behavior, 15, 249-255.

Wydell, T. N., Butterworth, B., \& Patterson, K. (1995). The inconsistency of consistency effects in reading: The case of Japanese Kanji. Joumal of Experiment Psychology: Leaming, Memory, and Cognition, 21, 1155-1168.

Wydell, T. N., Butterworth, B., Shibahara, N., \& Zorzi, M. (1997, July). The irregularity effects in reading: The case of Japanese Kanji. Paper presented at the meeting of the Experimental Psychology Society, Cardiff, Wales.

Appendix

Katakana and Kanji Words Used in Experiments 1-6 and Their English Translations

\begin{tabular}{|c|c|}
\hline \multicolumn{2}{|c|}{ Low frequency } \\
\hline Katakana & Kanji \\
\hline アイヌ(Ainu) & 分校 (branch school) \\
\hline ク゚ロリア (gloria) & 鉉山 (mine for natural resources) \\
\hline トランス (transfer) & 陣営 (camp) \\
\hline マカオ (Macao) & 端的 (frank, direct) \\
\hline スチール (steel) & 議決 (decision) \\
\hline マンモス (mammoth) & 側面 (side, aspect) \\
\hline テント (tent) & 金具 (metal fittings) \\
\hline レバー (lever, liver) & 解剖 (dissection) \\
\hline ダービー (the Derby) & 本位 (standard, center, self) \\
\hline シドニー (Sydney) & 発熱 (attack of fever) \\
\hline フライ (deep-fry) & 円滑 (smooth) \\
\hline ヒロイン (heroine) & 即売 (spot sale) \\
\hline バラード (ballade) & 苦戦 (hard fight, desperate battle) \\
\hline フレンド (fiiend) & 持続 (continuance, contimuation) \\
\hline ドクター (doctor) & 初恋 (one's first love) \\
\hline リポート (report) & 肉親 (blood relationship) \\
\hline \multicolumn{2}{|c|}{ High frequency } \\
\hline Katakana & Kanji \\
\hline ダイヤル (dial) & 報道 (news, information) \\
\hline アパート (apartment) & 格安 (bargain) \\
\hline アフリカ (Africa) & 芸能 (public entertainments) \\
\hline グループ (group) & 空港 (airport) \\
\hline ステレオ (stereo) & 整察 (police) \\
\hline ピアノ(piano) & 諥便 (mail) \\
\hline デパート(department store) & 質問 (question) \\
\hline センチ (centimeter) & 部分 (part, portion) \\
\hline センター (center) & 予想 (expectation, anticipation) \\
\hline サービス (service) & 外国 (foreign country) \\
\hline メーカー (manufacturer) & 番組 (program) \\
\hline ラジオ (radio) & 道路 (road, street) \\
\hline ホテル (hotel) & 会話 (conversation) \\
\hline フランス (France) & 店員 (salesclerk, shop assistant) \\
\hline スポーツ (sport) & 事件 (event, incident, affair) \\
\hline アジア (Asia) & 計画 (plan, project, scheme) \\
\hline
\end{tabular}

Received September 19, 1995 